\title{
Study on Integrated Control of Vehicle Yaw and Rollover Stability Using Nonlinear Prediction Model
}

\author{
Jianyong Cao, ${ }^{1,2}$ Lixin Jing, ${ }^{3}$ Konghui Guo, ${ }^{1}$ and Fan $\mathrm{Yu}^{1}$ \\ ${ }^{1}$ School of Mechanical Engineering, Shanghai Jiao Tong University, Shanghai 200240, China \\ ${ }^{2}$ Shanghai Motor Vehicle Inspection Center, Shanghai 201805, China \\ ${ }^{3}$ China Automotive Technology \& Research Center, Tianjin 300300, China \\ Correspondence should be addressed to Fan Yu; fanyu@sjtu.edu.cn
}

Received 4 February 2013; Revised 24 April 2013; Accepted 10 June 2013

Academic Editor: Pedro Ribeiro

Copyright (C) 2013 Jianyong Cao et al. This is an open access article distributed under the Creative Commons Attribution License, which permits unrestricted use, distribution, and reproduction in any medium, provided the original work is properly cited.

\begin{abstract}
This paper proposes the integrated controller of the yaw and rollover stability controls based on the prediction model. A nonlinear 3-DoF vehicle model with a piecewise linearization tire model is built up as the rollover predictive model, and its accuracy is verified by vehicle tests. A yaw stability controller and a rollover stability controller are proposed, respectively. Then coordinated control strategy is investigated for the integration of vehicle yaw and roll stability controls. The additional yaw torque and braking torque of each wheel are calculated. The unified command of valves is sent combined with ABS control algorithm. Virtual tests in CarSim are carried out, including slalom condition and double-lane change condition. Results indicate that the coordinated control algorithm improves vehicle yaw and roll stability effectively.
\end{abstract}

\section{Introduction}

Yaw and roll motions are two key lateral dynamic characteristics of the ground vehicles. The safety of driving vehicle is mainly dependent on yaw and rollover stability especially in emergency conditions. Yaw stability is the ability to keep vehicle turning and avoid the motion of skidding, and roll stability is to avoid vehicle turnover under certain lateral acceleration. In USA, the percentage of rollover occurrence in all crashes was about $2.7 \%$ in 2007 . However, the percentage of rollover occurrence in fatal crashes was about $21.5 \%$ and was significantly higher than that in injury and propertydamage-only crashes. Untripped rollovers account for less than $5 \%$ of rolled passenger vehicles in single-vehicle crashes, which often occur during high-speed collision avoidance manoeuvres [1]. Furthermore, rollovers account for nearly $33 \%$ of all deaths from sport utility vehicle (SUV), which, being popular in recent years, is considered to be easier to encounter rollover accident than other kinds of passenger vehicles for its higher gravity center and a lower rollover threshold [2-4]. Hence, it is necessary to design a rollover prevention controller.
Approaches proposed by researchers to prevent untripped rollover can be classified into three types. Using roller warning system, the first type controls the vehicle roll motions by the driver using roller warning systems indirectly. Rollover warning is one common method to prevent from rollover [5]. Rollover warning system predicts whether the vehicle has a rollover risk in the next time period based on the current driving state of the vehicle. Preston-Thomas and Woodrooffe developed one stability control and warning system on heavy vehicles in 1990. They used the lateral load transfer ratio (LTR) to indicate rollover threat [6]. Ervin et al. proposed a rollover stability advisor (RSA) system in 1998. This system determined the rollover acceleration threshold based on real-time measurements of the status of the vehicle [7]. Chen proposed a time-to-rollover (TTR) metric, which predicted the time to an impending rollover incident. A super real-time vehicle model is used in the metric, and future vehicle states can be predicted in real-time [8]. The second type controls vehicle roll motions using active antiroll bar [9], continuous damping control (CDC) [10], or active suspension control [11] to enhance the rollover stability through influencing the lateral load transfer and longitudinal 
speed control $[12,13]$. It can prevent rollover by increasing the rollover thresholds. The third type utilizes integrated chassis control (ICC), which consists of active front steering, yaw stability control (YSC) and active/semiactive suspension, active antiroll bar (AARB), and so on. Some studies have shown that integration of individual modular chassis control systems is a more efficient method to improve vehicle stability and handling [14-16]. Recently, Chou and D'Andréa-Novel proposed a global vehicle control system using differential braking torques and active suspension forces [17]. Yoon et al. designed an integrated system by using YSC and active antiroll bar [12]. Li et al. developed a coordinated system by using direct yaw moment, active steering, and active stabilizer [18]. By integrating electronic stability control, active front steering, and continuous damping control, Yoon et al. proposed unified chassis control strategy to prevent rollover and improve lateral stability [19].

Among these three types, the third one would have the better performance than the other two. However, multiple actuators are needed and complexity would be increased. Among those ICC, the YSC contributes to maintain vehicle yaw stability by reducing the lateral acceleration through controlling the longitudinal speed [20-22], and the differential braking is only used to reduce the lateral acceleration. It is unable to obtain the roll motions information of the vehicle as rollover warning system. The roll motions may deteriorate the maneuverability of the vehicle and vice versa. So, in this paper, a novel coordinated control system is proposed, which controls the vehicle yaw and rollover stability only using the differential braking based on the devices of YSC. In detail, a nonlinear prediction model-based vehicle TTR estimator is designed to predict an impending rollover incident for the YSC system. Then the coordinate system of RSC and YSC is proposed. However, the difficult task for the coordinate system is to obtain TTR properly. To overcome this problem, a 3DoF vehicle model considering tire nonlinear characteristics is proposed to calculate the load transfer ratio online, which can estimate the rollover characters of the vehicle. At last, the controller of the coordinate system is designed by using PI and $\mathrm{P}$ control method.

Taking an SUV as the research object, whose parameters were given in Table 1, the coordinated control of RSC and YSC is studied on the basis of in-depth study of the yaw and roll stability controls. The presentation of this paper is organized as follows. Section 2 provides the derivation detail of a nonlinear 3-DoF vehicle model with a piecewise linearization tire model, whose parameters can be identified and verified. In Section 3, the proposed controller is described. In Section 4, simulations are performed on CarSim and the results are discussed. Section 5 gives the conclusion of this paper.

\section{Vehicle Dynamics Model}

This section describes a three-degree-of-freedom roll prediction model, which is shown in Figure 1, taking ISO vehicle coordinate system. A roll degree-of-freedom is considered on the basis of two-degree-of-freedom vehicle nonlinear prediction model, including a lateral movement along the
TABLE 1: Parameter list of vehicle model.

\begin{tabular}{lc}
\hline Element & Value \\
\hline Vehicle mass $/ \mathrm{kg}$ & 1910 \\
Sprung mass of vehicle $/ \mathrm{kg}$ & 1664 \\
$\begin{array}{l}\text { Distance between the center of sprung mass and the } \\
\text { vehicle roll axis/m }\end{array}$ & 0.316 \\
$\mathrm{CG}$ height $/ \mathrm{m}$ & 0.55 \\
$\mathrm{CG}$ to rear axis $/ \mathrm{m}$ & 1.165 \\
Inertia around the $z$-axis $/ \mathrm{Kg} * \mathrm{~m}^{2}$ & 3089.2 \\
Inertia around the $z$-axis and $x$-axis $/ \mathrm{Kg} * \mathrm{~m}^{2}$ & 33.2 \\
Inertia around the $z$-axis of sprung $\mathrm{mass} / \mathrm{Kg} * \mathrm{~m}^{2}$ & 2549.7 \\
Inertia around the $z$-axis and $x$-axis of sprung & 32.1 \\
mass $/ \mathrm{kg} * \mathrm{~m}^{2}$ & 1.411 \\
CG to front axis $/ \mathrm{m}$
\end{tabular}

$y$-axis, a yaw motion around the $z$-axis, and a roll motion around the $x$-axis [23]. Some other assumptions are made in order to simplify the motion equations. The principal hypotheses are as follows.

(i) Small perturbations from straight running at constant forward speed on the flat and level road are neglected.

(ii) The front wheel steering angle is taken as model input.

(iii) The vertical motion and pitching motion are neglected when the vehicle is on the flat and level road.

(iv) Aerodynamic effects are neglected.

(v) Change of tire characteristic and the aligning torque are neglected.

(vi) Axle lateral stiffness considers steering system stiffness, suspension stiffness, and tire lateral elasticity.

(vii) The location of the center of gravity is fixed.

Based on the above assumptions, the balance equations of the force along the $y$-axis and torques around the $z$-axis and $x$-axis can be expressed as

$$
\begin{gathered}
\sum F_{y}=m \cdot\left(r \cdot V_{x}+\dot{V}_{y}\right)-m_{s} \cdot e \cdot \ddot{\varphi} \\
\sum M_{z}=I_{z} \cdot \dot{r}+I_{x z} \cdot \ddot{\varphi} \\
\sum M_{x}=I_{x s} \cdot \ddot{\varphi}-m_{s} \cdot e \cdot\left(r \cdot V_{x}+\dot{V}_{y}\right)+I_{x z s} \cdot \dot{r} .
\end{gathered}
$$

External forces can be expressed as

$$
\begin{gathered}
\sum F_{y}=F_{y f}+F_{y r}=k_{f} \cdot \alpha_{f}+k_{r} \cdot \alpha_{r}, \\
\sum M_{z}=a \cdot F_{y f}+b \cdot F_{y r}=a \cdot k_{f} \cdot \alpha_{f}-b \cdot k_{r} \cdot \alpha_{r}, \\
\sum M_{x}=m_{s} \cdot g \cdot e \cdot \varphi-K_{\varphi} \cdot \varphi-C_{\varphi} \cdot \dot{\varphi} .
\end{gathered}
$$

As a roll prediction model, vehicle model with three degrees-of-freedom should represent the real vehicle. When 


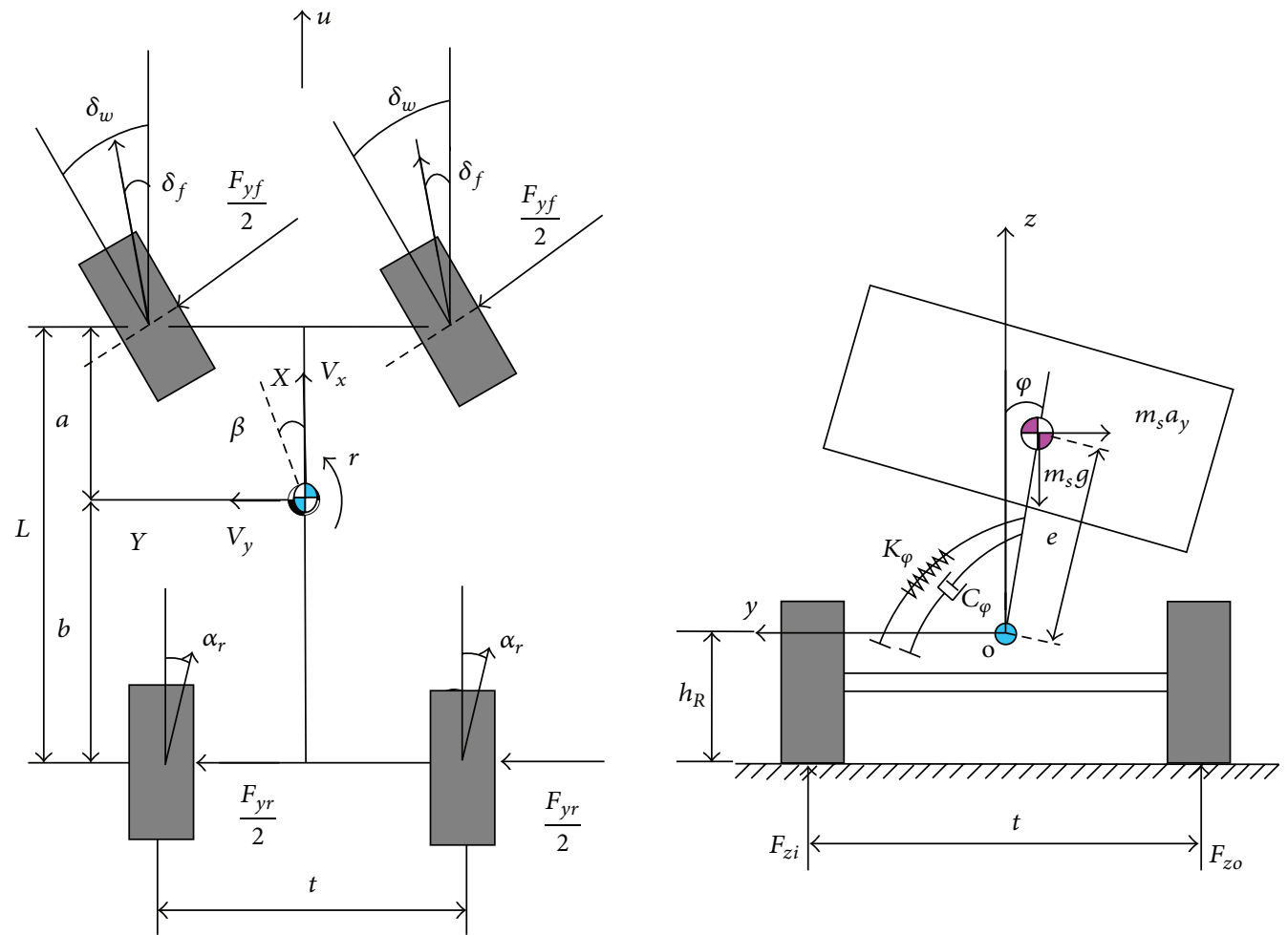

FIgURE 1: 3-DoF vehicle nonlinear prediction model schematic diagram.

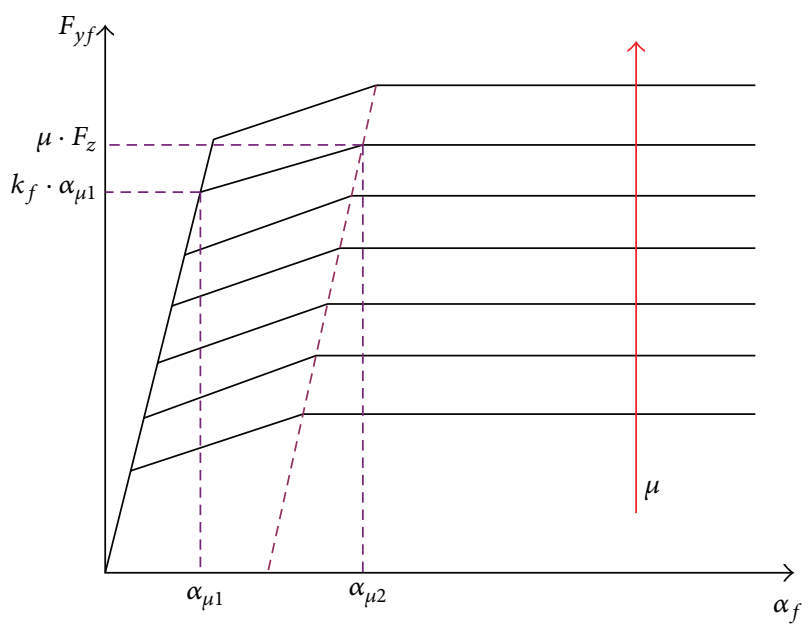

FIGURE 2: Diagram of simplified front wheel sideslip characteristics.

rollover occurs, the lateral acceleration of vehicle will generally reach a larger value, and then the lateral forces of tires are in a nonlinear area. In this case, the limit of tire's lateral force due to road adhesion limit should be considered. In order to provide vehicle yaw stability and avoid oversteer caused by lateral force saturation of rear wheel, the saturation restriction is used for front wheel only. The cornering property of front wheel is nonlinear and that of the rear wheel is linear,

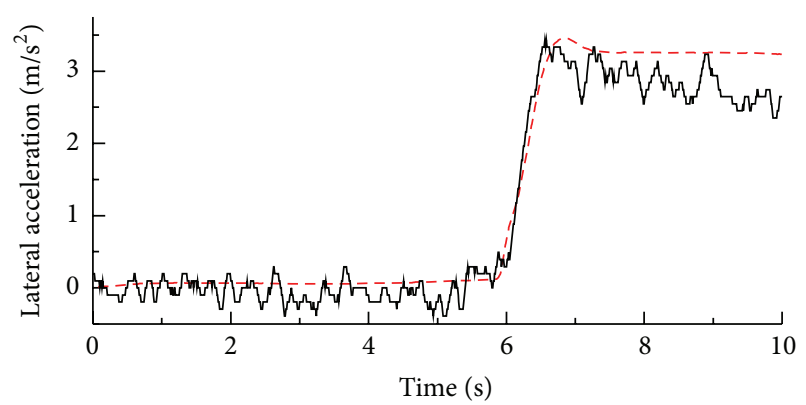

Test data

- - - Simulation

FIGURE 3: Steering wheel angle step input test.

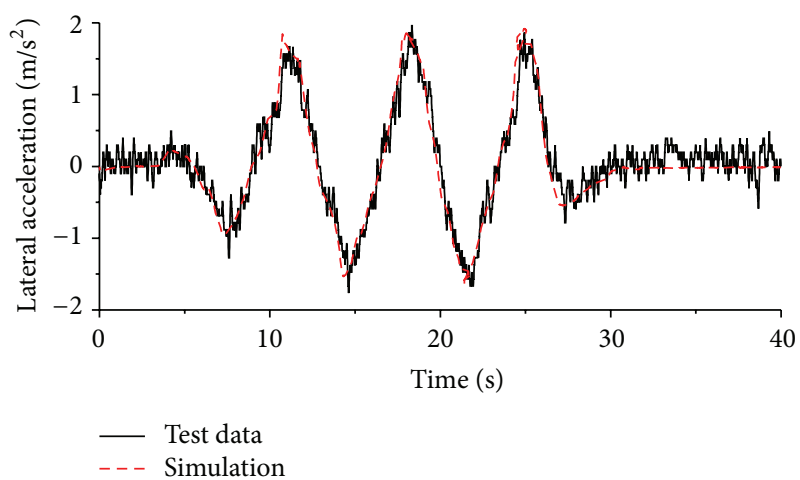

Figure 4: Slalom test $(30 \mathrm{~km} / \mathrm{h})$. 


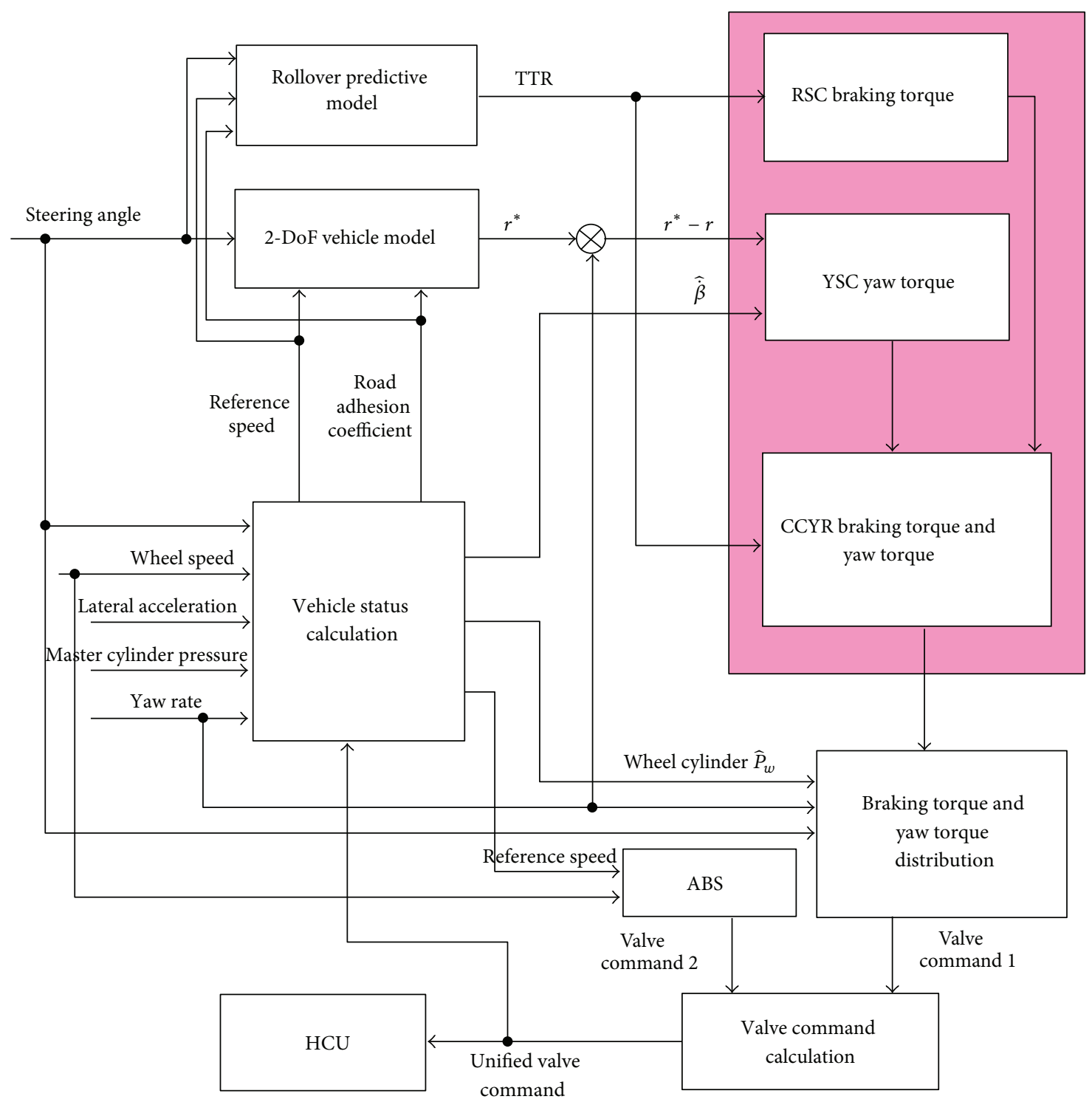

FIGURE 5: Overall structure of coordinated control algorithm of vehicle yaw and rollover stability.

respectively. The cornering characteristic of front tire is piecewise, and the lateral force is obtained as follows:

$$
\begin{aligned}
& F_{y f} \\
& \quad= \begin{cases}k_{f} \cdot a_{f} & a_{f} \leq a_{\mu 1} \\
k_{f} \cdot a_{\mu 1}+\frac{\mu F_{z f}-k_{f} \cdot a_{\mu 1}}{a_{\mu 2}-a_{\mu 1}}\left(a_{f}-a_{\mu 1}\right) & a_{\mu 1} \leq a_{f} \leq a_{\mu 2} \\
\mu \cdot F_{z f} & a_{f} \geq a_{z f},\end{cases}
\end{aligned}
$$

where $a_{\mu 1}$ and $a_{\mu 2}$ are sideslip angles, respectively, which correspond to the turning point of cornering characteristics when the road friction coefficient is $\mu \cdot a_{f}$ is front wheel sideslip angle. $F_{z f}$ is front wheel vertical load, and the diagram is shown in Figure 2.

A 3-DOF vehicle model is derived from (1)-(3), and the parameters $\left(k_{f}, k_{r}, K_{\varphi}, C_{\varphi}\right)$ of the model can be identified through the input/output data of the vehicle test data table. A typical signal, for example, step test, is chosen as driver steering wheel input to obtain the vehicle lateral acceleration as the output. Meanwhile, the same signal is also as the input of 3-DOF vehicle model in simulation. Using the errors of $a_{y}$ and $\widetilde{a}_{y}$, an objective function in (4) is employed to optimize the vehicle parameters:

$$
J=\int_{0}^{t_{0}}\left(a_{y}-\tilde{a}_{y}\right)^{2} d t
$$

The 3-DoF vehicle dynamics model is verified by vehicle handling and stability experiment data. The main contents of the experimental verification include vehicle steady-state roll characteristics and steady-state cornering performance, vehicle transient steering characteristics, and steer oncenter characteristics and returnability. The constant-speed variable-steer tests are carried out on a uniform, dry, level 


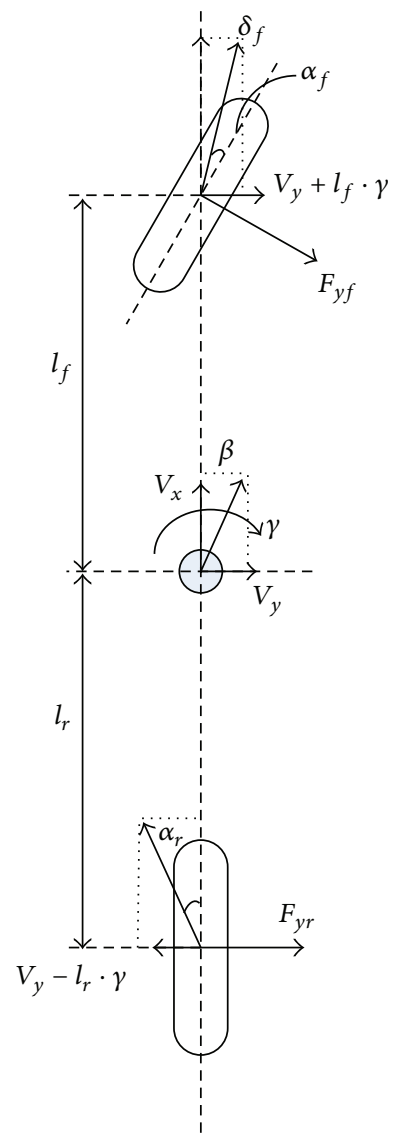

Figure 6: Bicycle model.

and hard road surface. A step input of steering wheel angle is applied when the vehicle runs at a constant-speed, and the slalom test was carried out at a speed of $30 \mathrm{~km} / \mathrm{h}$. Vehicle data are recorded at sampling rate of $200 \mathrm{~Hz}$. The results show that the responses of the vehicle model coincide with the actual vehicle measurements (see Figures 3 and 4).

\section{Coordinated Control Algorithm of Vehicle Yaw and Rollover Stability}

The objectives of YSC and RSC are to follow the driver intention and limit the maximum of the vehicle lateral acceleration, respectively. In order to maximize the vehicle yaw and roll stability, YSC and RSC will be integrated in this section. Figure 5 indicates the cascade structure of the control algorithm, which consists of three levels. First, a 3 -DoF rollover prediction model and a 2-DoF single-track model are implemented to obtain the roll track error and the yaw track error, respectively. Then an RSC braking torque controller and a YSC yaw moment controller are established to generate a desired torque control input based on the errors obtained previously, and the coordinated control of yaw and rollover (CCYR) stability controllers is applied to coordinate the demand of these two controllers based on the TTR. In the underlying structure, the braking torque and the yaw moment are distributed to each wheel and achieved by the hydraulic control unit (HCU) valve controller, and the ABS controller is also used to prevent wheel lock. In addition to the cascaded control logic, a vehicle status observer is implemented to obtain the status used in the controller which includes reference longitudinal speed and lateral speed, road adhesion coefficient, vehicle sideslip angle, wheel rotation speed, and wheel cylinder pressure.

3.1. Design of YSC. YSC is designed to enhance vehicle maneuverability by tracking a reference yaw rate generated by a driver's steering input. The yaw moment control is adopted to generate a desired yaw moment in order to reduce the yaw rate error between the reference and actual yaw rate. A linear bicycle model is used to compute the reference yaw rate, and Figure 1 shows the 3 -DoF model, including the direct yaw moment.

In order to obtain the reference yaw rate and vehicle sideslip angle, a single-track model is proposed. As is shown in Figure 6, yaw and lateral motion in the bicycle model can be obtained as follows:

$$
\begin{gathered}
m V_{x}(\dot{\beta}+\gamma)=F_{y f}+F_{y r}, \\
I_{z} \dot{\gamma}=F_{y f} l_{f}-F_{y r} l_{r} .
\end{gathered}
$$

The wheel lateral force is considered to be linear with the tire slip angle:

$$
\begin{gathered}
F_{y f}=k_{f} \alpha_{f}, \\
F_{y r}=k_{r} \alpha_{r}, \\
\alpha_{f}=\delta_{f}-\frac{V_{y}+l_{f} \gamma}{V_{x}}, \\
\alpha_{r}=\frac{V_{y}-l_{r} \gamma}{V_{x}} .
\end{gathered}
$$

Therefore, the transfer function of yaw rate and sideslip angle can be obtained:

$$
\begin{aligned}
& \frac{\gamma}{\delta}(s)=G_{r} \frac{\tau_{1} s+1}{T_{1} s^{2}+T_{2} s+1}, \\
& \frac{\beta}{\delta}(s)=G_{\beta} \frac{\tau_{1}^{\prime} s+1}{T_{1} s^{2}+T_{2} s+1},
\end{aligned}
$$

where

$$
\begin{gathered}
G_{r}=\frac{V_{x} \tan \delta_{f}}{l i_{L}\left[1+\left(V_{x} / V_{\mathrm{ch}}\right)^{2}\right]}, \quad G_{\beta}=\frac{l_{r}-m l_{f} V_{x}^{2} / k_{r} l}{l\left[1+\left(V_{x} / V_{\mathrm{ch}}\right)^{2}\right]}, \\
\tau_{1}=\frac{m V_{x} l_{f}}{l k_{\gamma}}, \quad \tau_{1}^{\prime}=\frac{I_{z}}{b k_{\gamma} / V_{x}-m V_{x} l_{f}}, \\
T_{1}=\frac{m V_{x}^{2} I_{z}}{l^{2} k_{f} k_{r}\left(1+V_{x}^{2} / V_{\mathrm{ch}}^{2}\right)},
\end{gathered}
$$




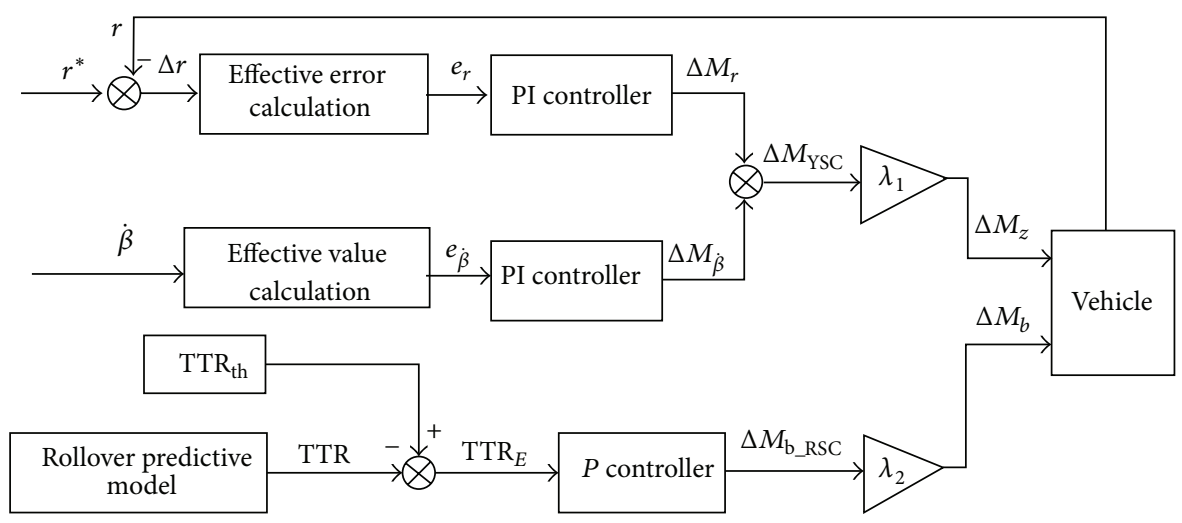

FIgURE 7: Diagram of the additional yaw moment and brake torque.
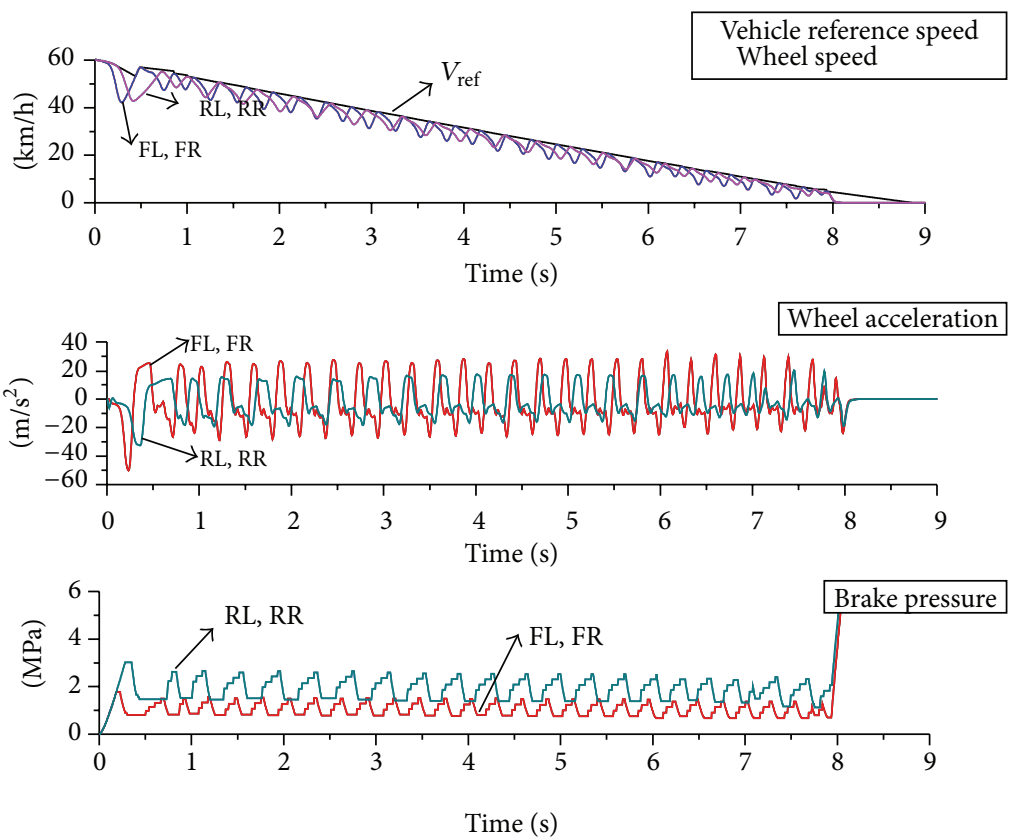

FIGURE 8: Braking in low adhesion road.

$$
\begin{gathered}
T_{2}=\frac{V_{x}\left[I_{z}\left(k_{f}+k_{r}\right)+m\left(l_{f}^{2} k_{f}+l_{r}^{2} k_{r}\right)\right]}{l^{2} k_{f} k_{r}\left(1+V_{x}^{2} / V_{\mathrm{ch}}^{2}\right)}, \\
V_{\mathrm{ch}}^{2}=\frac{k_{f} k_{r} l^{2}}{m\left(k_{r} l_{r}-k_{f} l_{f}\right)} .
\end{gathered}
$$

Hence, the steady-state response of yaw rate and sideslip angle can be obtained as follows:

$$
\gamma_{\text {state }}=G_{\gamma} \delta_{f}, \quad \beta_{\text {state }}=G_{\beta} \delta_{f} .
$$

In addition, the tire-road adhesion limitation is taken into account:

$$
\gamma_{\max }=\frac{\mu g}{V_{x}}
$$

Therefore, the nominal yaw rate can be obtained as

$$
\gamma_{N 0}=\min \left\{\left|\gamma_{\text {state }}\right|,\left|\frac{\mu g}{V_{x}}\right|\right\} \operatorname{sign}\left(\delta_{f}\right) .
$$

Similarly, the nominal vehicle sideslip angle could also be obtained by the steady-state response and the tire-road friction limitation:

$$
\beta_{N 0}=\min \left\{\left|\beta_{N}\right|,|\arctan (0.02 \mu g)|\right\} \operatorname{sign}\left(\delta_{w}\right) .
$$

The strategy of yaw rate control method takes the deviation $e$ between the actual yaw rate and the reference yaw rate as a control variable. When the absolute value of the deviation $e$ exceeds the threshold set by control algorithm, the vehicle should be in an instability state and needs to intervene yaw moment [24]. The additional yaw moment $\Delta M$ demanded by YSC can be expressed, denoting the error between the 

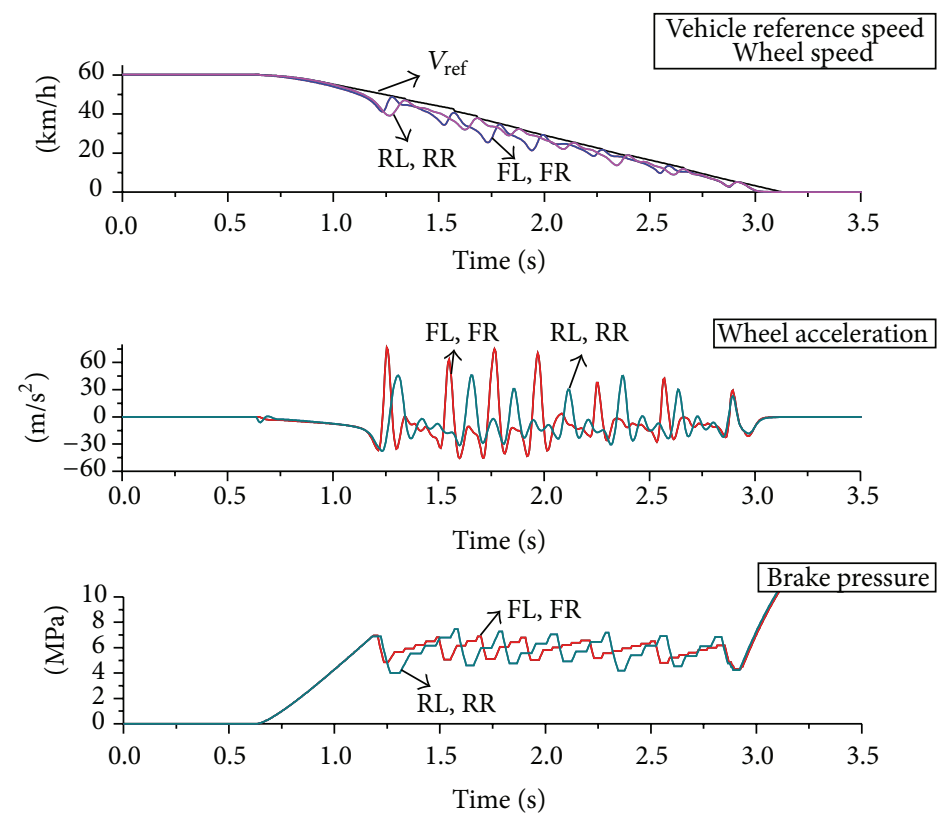

FIgURE 9: Braking in high adhesion road.
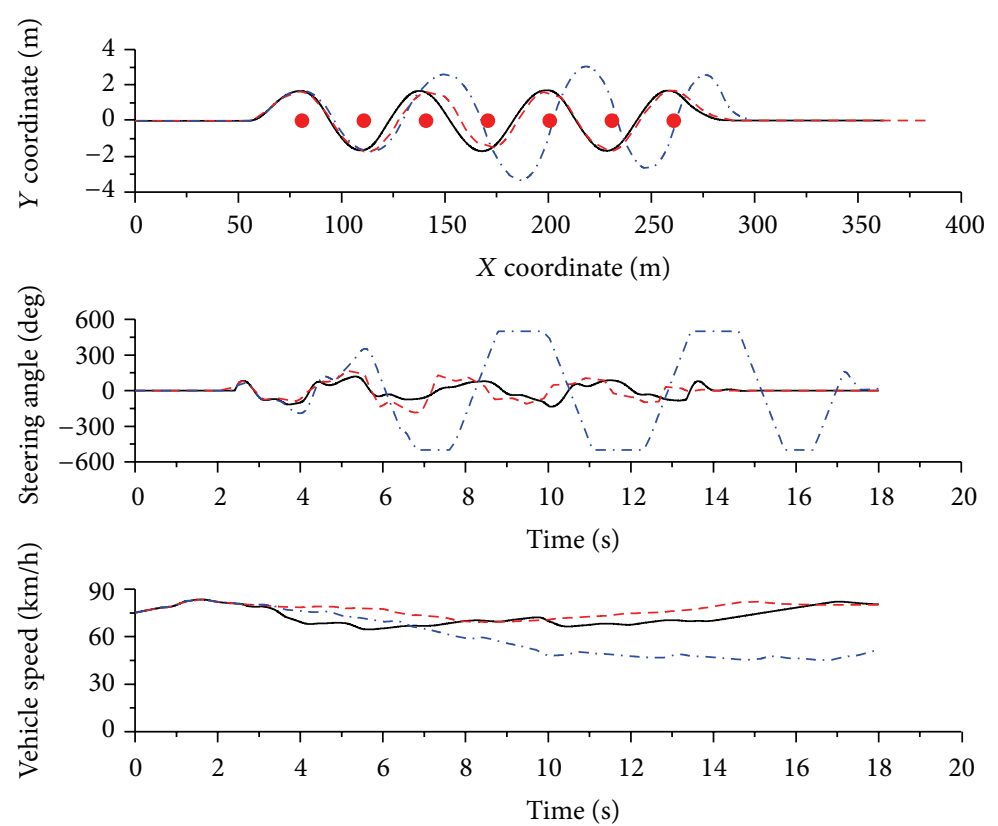

— With CCYR

- - - Only with YSC

... Only with RSC

FIGURE 10: Driving track, steering wheel angle, and vehicle speed.

nominal yaw motion and sideslip angle and the actual value of them, respectively, as follows:

$$
\begin{aligned}
& e_{\gamma}(n)=\gamma_{N 0}(n)-\gamma(n), \\
& e_{\beta}(n)=\beta_{N 0}(n)-\beta(n) .
\end{aligned}
$$

And the desired yaw moment can be obtained from the yaw error and vehicle sideslip angle error:

$$
\begin{aligned}
& \Delta M_{\gamma}=K_{\gamma p} \Delta e_{\gamma}(n)+K_{\gamma i} e_{\gamma}(n), \\
& \Delta M_{\beta}=K_{\beta p} \Delta e_{\beta}(n)+K_{\beta i} e_{\beta}(n),
\end{aligned}
$$

where $K_{\gamma p}, K_{\gamma i}, K_{\beta p}$, and $K_{\beta i}$ are controller parameters. 


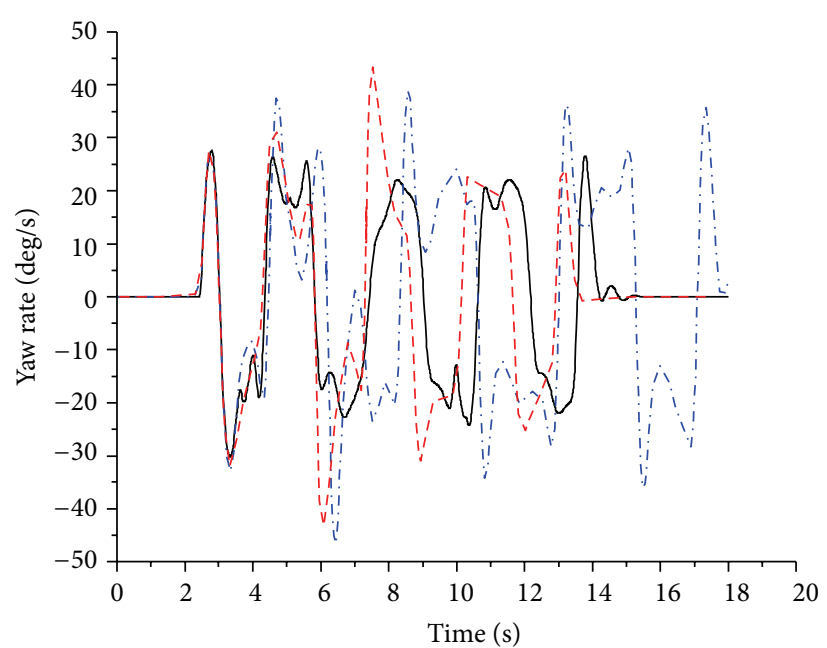

(a)

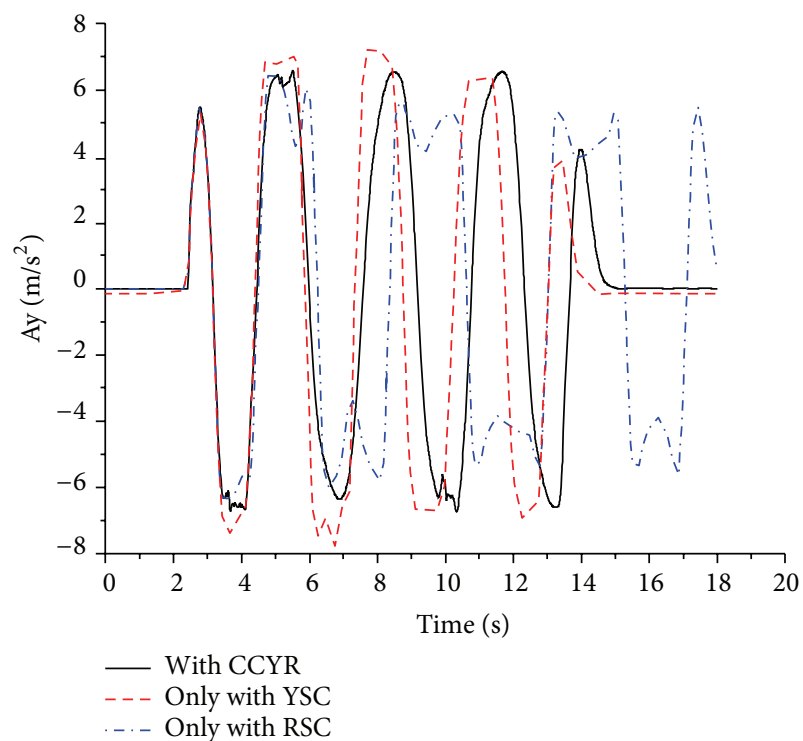

(c)

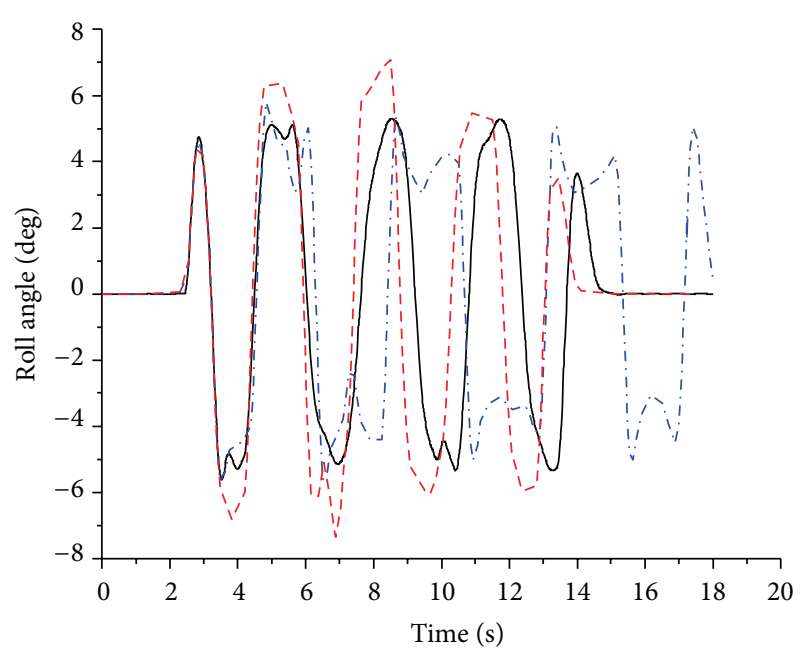

(b)

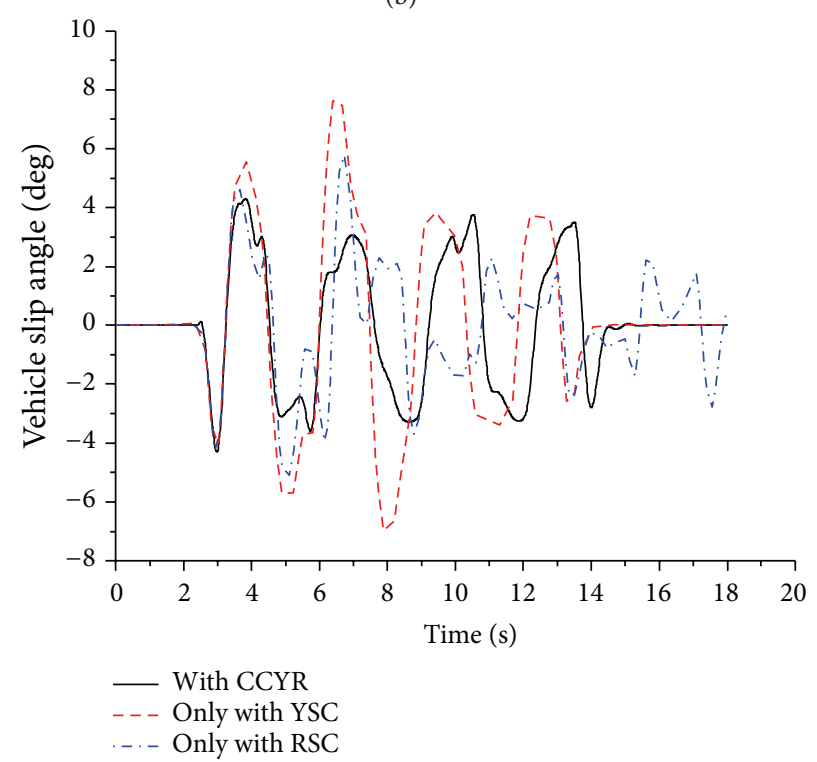

(d)

FIGURE 11: Yaw rate, roll angle, lateral acceleration, and sideslip angle.

A weight is used to obtain the desired moment of the YSC as follows:

$$
\Delta M_{\mathrm{YSC}}=(1-\alpha) \Delta M_{\gamma}+\alpha \Delta M_{\beta} \text {, }
$$

where $\alpha$ is a positive weight coefficient up to 1 and $\alpha$ increases as the vehicle sideslip angle increases.

3.2. Design of RSC. RSC is designed to generate a target braking force to reduce the lateral acceleration based on the
LTR, while the brake intervention is decided on the TTR threshold. Both TTR and LTR are calculated based on the 3 -DoF vehicle nonlinear prediction model described in the second section, and with denoting $x=\left[\begin{array}{llll}\beta & \gamma & \dot{\varphi} & \varphi\end{array}\right]$ the vehicle model can be transferred to the state-space model as follows:

$$
\dot{x}=A x+B \delta,
$$

where $\dot{\varphi}$ is the roll rate of vehicle body.

Consider

$$
\begin{gathered}
A=M^{-1} N, \quad B=M^{-1} P, \\
M=\left[\begin{array}{cccc}
I_{z} & 0 & I_{x z s} & 0 \\
0 & m V_{x} & -m_{s} e & 0 \\
I_{x z s} & -m_{s} e V_{x} & I_{x s} & 0 \\
0 & 0 & 0 & 1
\end{array}\right],
\end{gathered}
$$




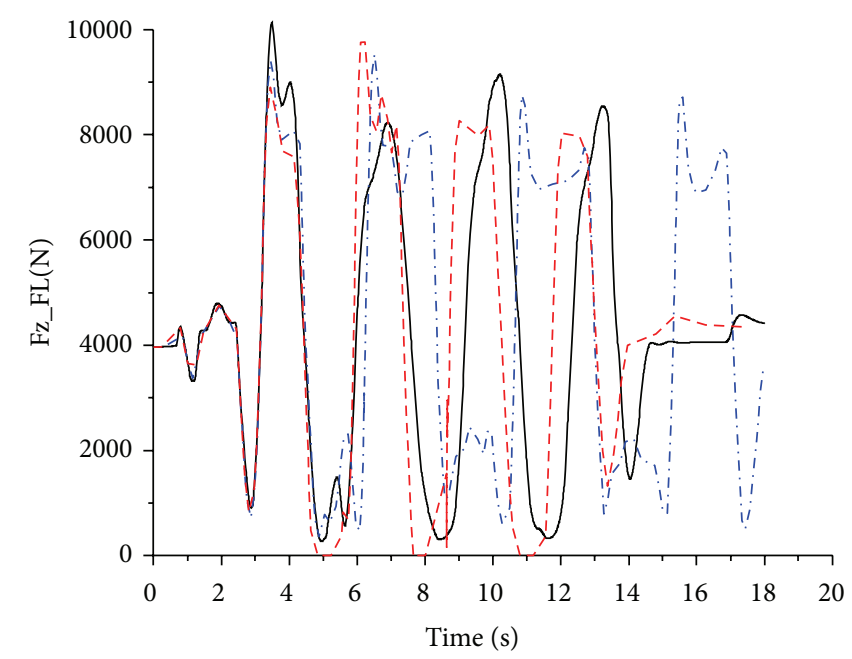

(a)

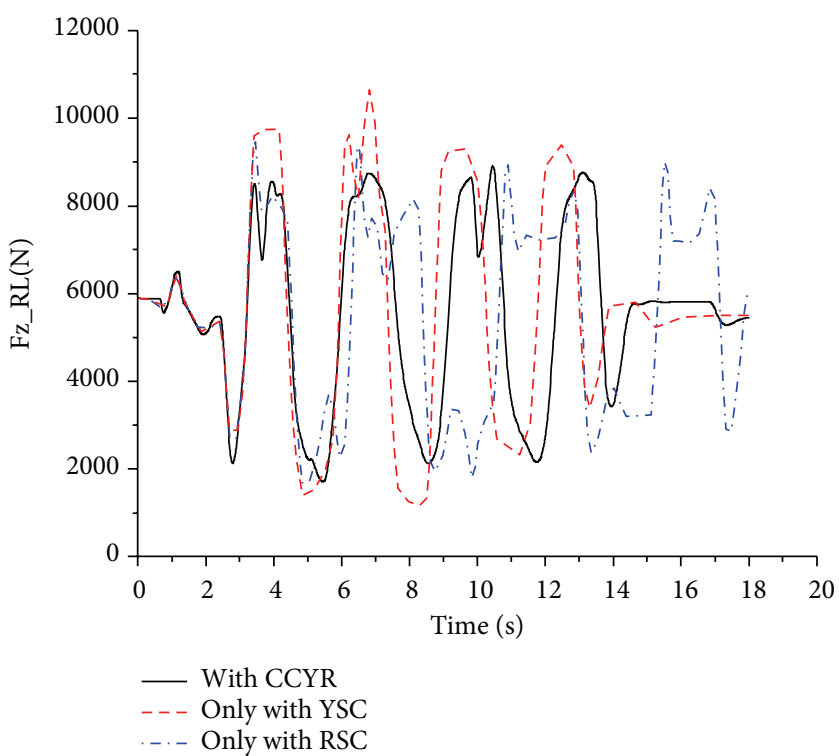

(c)

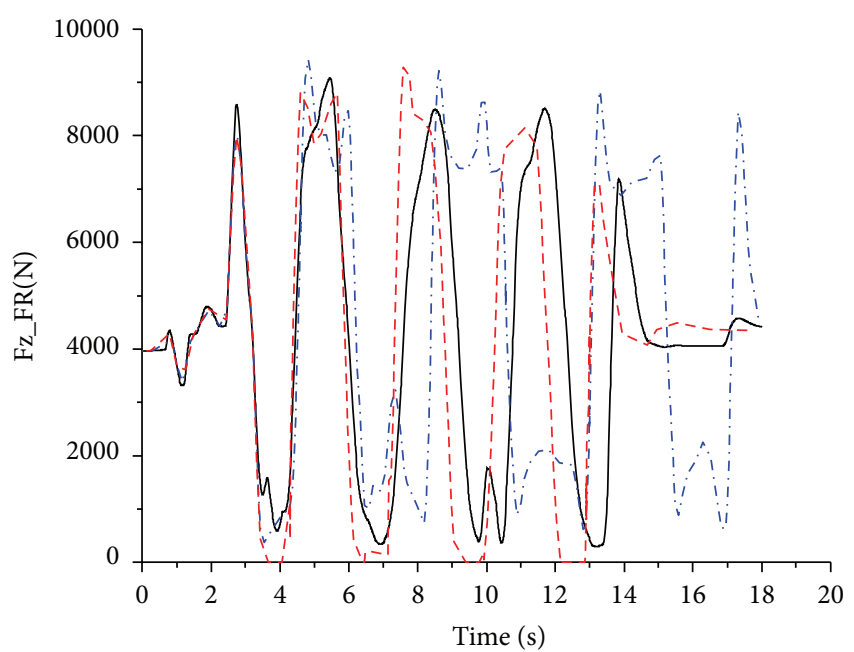

(b)

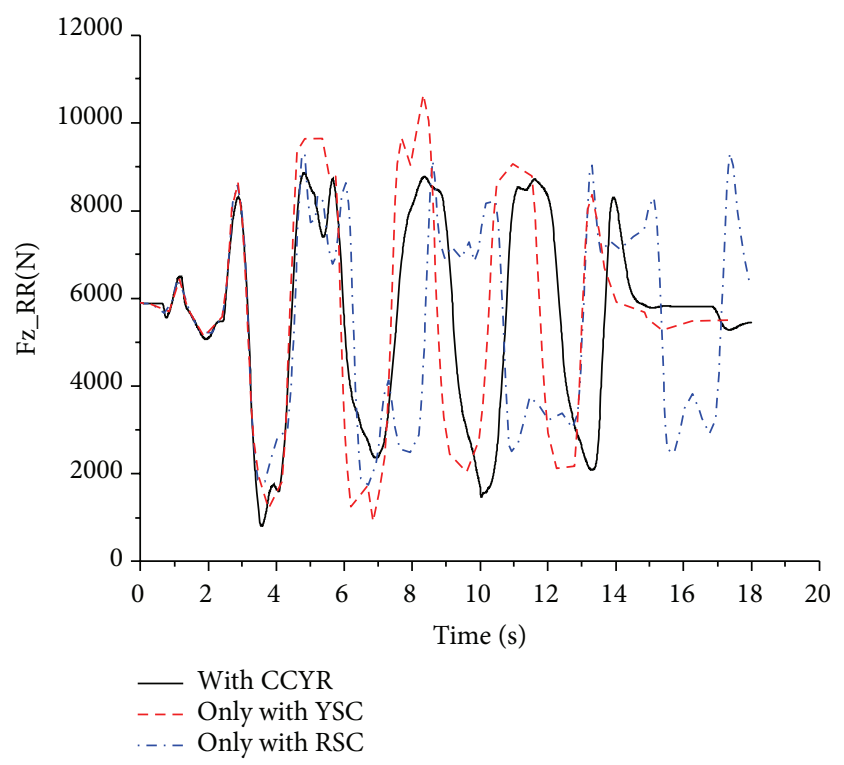

(d)

FIGURE 12: Wheel vertical force.

$$
N=\left[\begin{array}{cccc}
-2\left(\frac{k_{f} a^{2}+k_{r} b^{2}}{V_{x}}\right) & 2\left(-a k_{f}+b k_{r}+N_{f}+N_{r}\right) & 0 & 2\left(a E_{f} k_{f}-b E_{r} k_{r}\right) \\
2\left(\frac{-a k_{f}+b k_{r}}{V_{x}}\right)-m V_{x} & -2\left(k_{f}+k_{r}\right) & 0 & 2\left(E_{f} k_{f}+E_{r} k_{r}\right) \\
m_{s} e V_{x} & 0 & -C_{\phi} & m_{s} g e-K_{\phi} \\
0 & 0 & 1 & 0
\end{array}\right],
$$




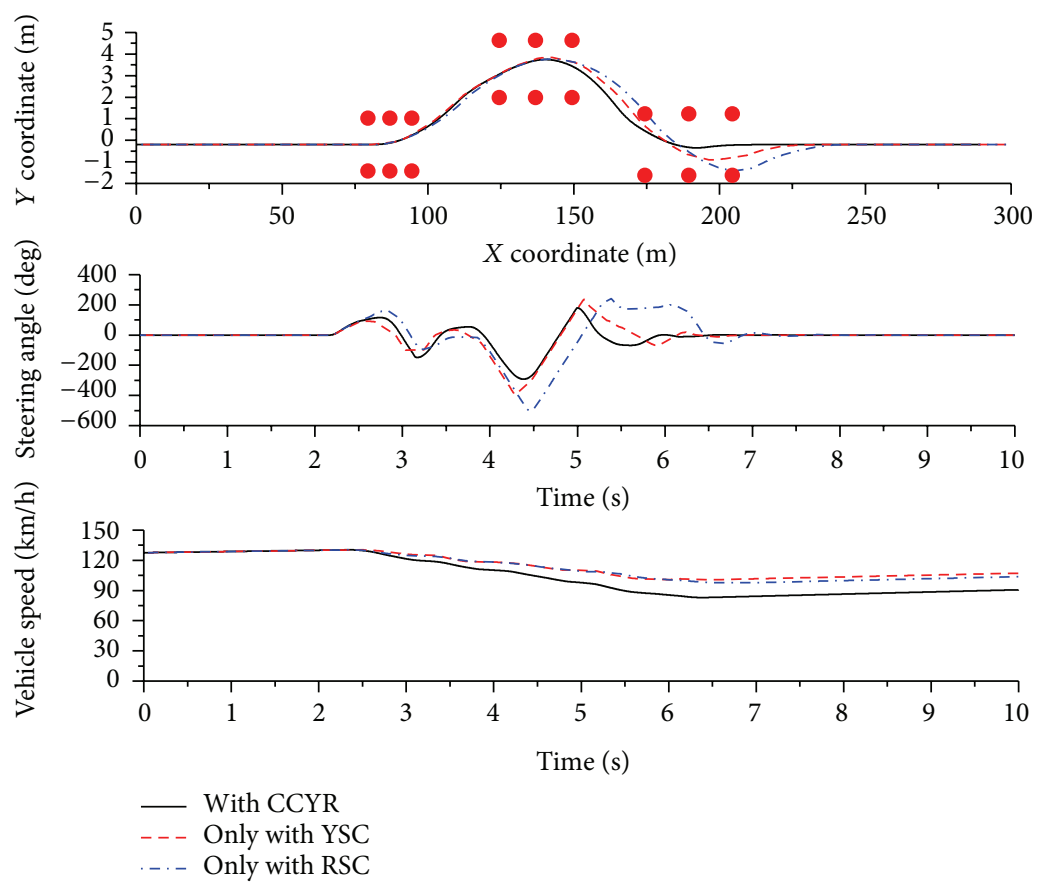

FIGURE 13: Driving track, steering wheel angle, and vehicle speed.

LTR can be defined as

$$
\operatorname{LTR}=\frac{\left|\sum_{i=1}^{n}\left(\mathrm{FL}_{i}-\mathrm{FR}_{i}\right)\right|}{\sum_{i=1}^{n}\left(\mathrm{FL}_{i}-\mathrm{FR}_{i}\right)} .
$$

The roll dynamic can be described by

$$
-\mathrm{FR} \frac{t}{2}+\mathrm{FL} \frac{t}{2}-K_{\varphi} \varphi-C_{\varphi} \dot{\varphi}=0 .
$$

Hence, the LTR can be obtained from the previous equation:

$$
\mathrm{LTR}_{\text {estamit }}=-\frac{2\left(C_{\varphi} \dot{\varphi}+K_{\varphi} \varphi\right)}{m g t} .
$$

So LTR can be obtained from the sate space model as follows:

$$
\mathrm{LTR}_{\text {estamit }}=C_{\mathrm{LTR}} x
$$

where

$$
C_{\text {LTR }}=\left[\begin{array}{llll}
0 & 0 & -\frac{2 C_{\varphi}}{m g t} & -\frac{2 K_{\varphi}}{m g t}
\end{array}\right] .
$$

TTR $_{\text {estamit }}$ is calculated according to the $\mathrm{LTR}_{\text {estamit }}$ at the current state with the proposed 3-DoF vehicle model online. A TTR threshold $\mathrm{TTR}_{N 0}$ is used to control the braking intervention of RSC:

$$
e_{\mathrm{TTR}}(n)=\operatorname{TTR}_{N 0}(n)-\mathrm{TTR}_{\text {estamit }}(n) .
$$

The error between the nominal TTR and the estimated TTR is used to calculate the braking yaw moment of the RSC with a proportional controller, where $K_{\varphi p}$ is the parameter:

$$
\Delta M_{b \_\mathrm{RSC}}=K_{\varphi p} e_{\mathrm{TTR}} \operatorname{sign}\left(\delta_{f}\right) .
$$

3.3. Design of CCYR Stability Controller. The safety of driving vehicle is mainly dependent on yaw and rollover stability. Unstability of yaw takes place on all roads, while rollover mainly happens on the high adhesion road. So YSC mainly works on the low adhesion road alone, while YSC and RSC may be simultaneously or separately triggered on the high adhesion road. There are two conditions when YSC and RSC simultaneously trigger. One, when vehicle exists the danger of oversteer and rollover at the same time, YSC and RSC make vehicle tend to understeer. The other, when the rollover takes place, RSC gradually intervenes the control system which leads to larger understeer of the vehicle. Then the understeer of vehicle triggers the YSC which makes the vehicle tend to oversteer.

Overall, there are three primary relationships between YSC and RSC.

(1) When separately triggered, YSC and RSC are independent and maximize achievement of the control target separately.

(2) When simultaneously triggered in line with control trend, YSC and RSC control the system at the same time with coupling interaction.

(3) When simultaneously triggered in contrast to control trend, there is contradiction between YSC and RSC.

Hence, the control targets are to keep yaw and rollover stability and reduce contradiction between YSC and RSC, and coordinate those two controllers working as an integration to ensure vehicle stability according to the danger level of yaw and roll. 


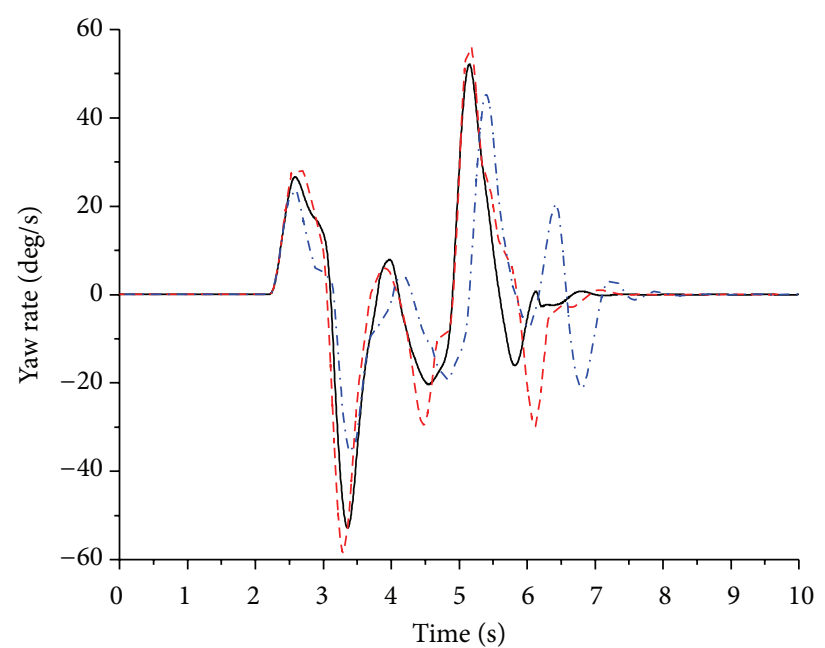

(a)

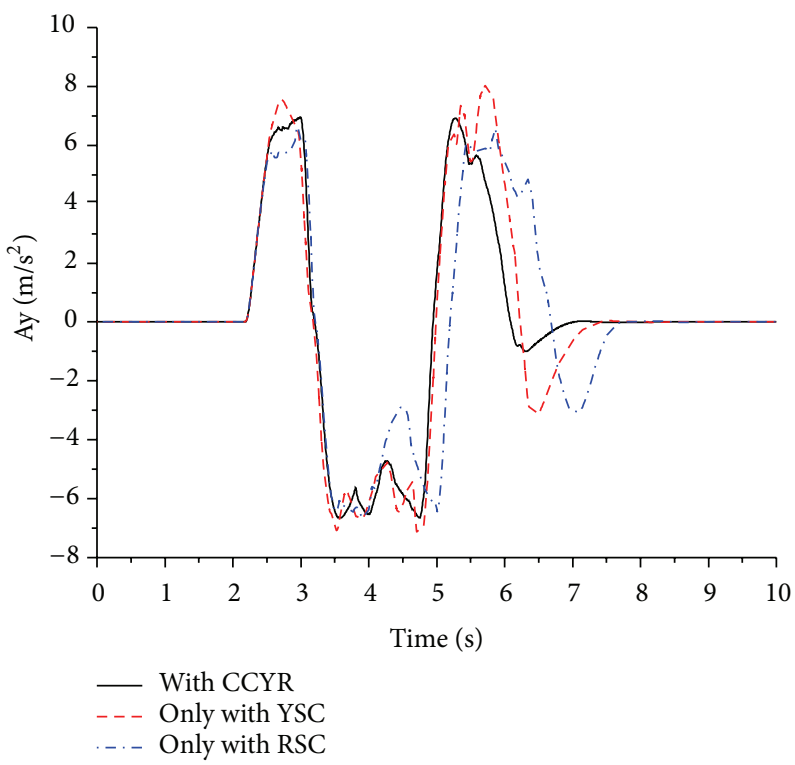

(c)

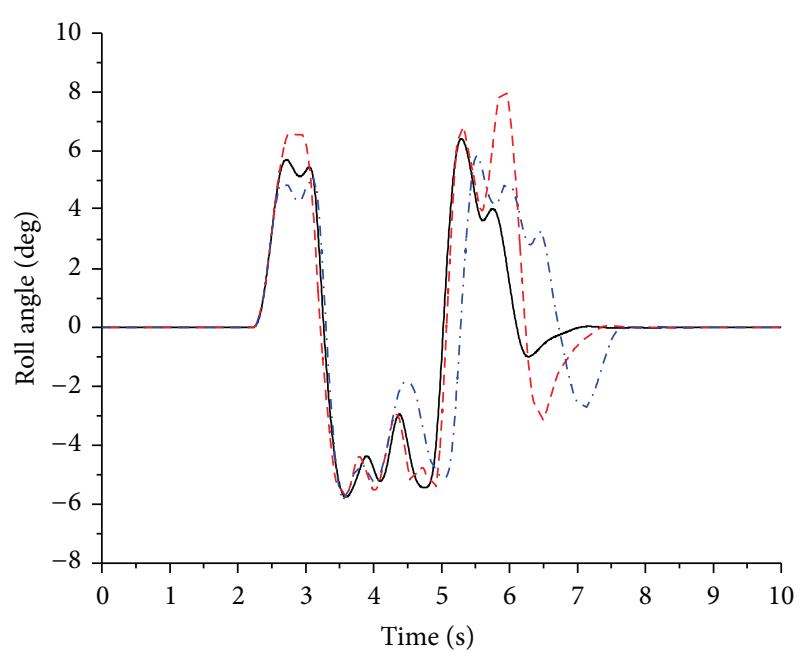

(b)

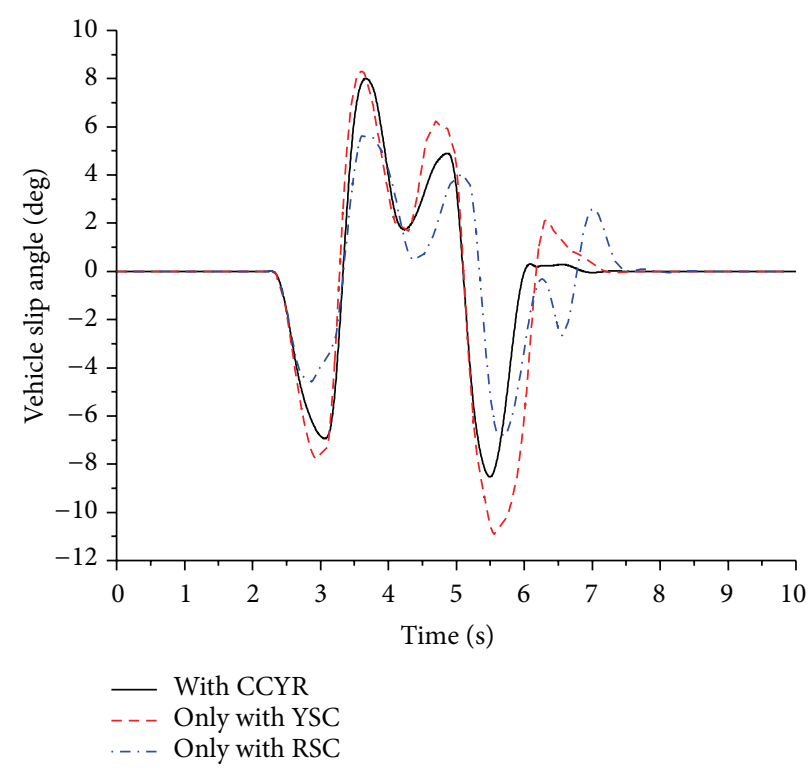

(d)

FIGURE 14: Yaw rate, roll angle, lateral acceleration, and sideslip angle.

Coordinated control of yaw and rollover stability controllers is designed to coordinate the YSC and RSC, shown in Figure 7.

The additional yaw moment $\Delta M$ is generated by applying braking forces. In the research, the braking torqueses are applied to the diagonal wheels based on detection of the understeer and oversteer during driving situation. When the vehicle has characteristic of understeer, the braking force is applied on the inside front wheel. Similarly the braking force is applied on the outside rear wheel when the vehicle has characteristic of oversteer. The control algorithm calculates the braking force of each wheel based on the states of vehicle and the value of the additional yaw moment $\Delta M$ :

$$
\Delta M=\lambda_{1} \Delta M_{\mathrm{YSC}}+\lambda_{2} \Delta M_{b_{-} \mathrm{RSC}},
$$

where $\lambda_{1}$ and $\lambda_{2}$ are chosen carefully according to the vehicle state and $\lambda_{1}$ and $\lambda_{2}$ emphasize the importance of yaw stability and rollover stability, respectively. In order to obtain $\lambda_{1}$ and $\lambda_{2}$, the normalization coefficients $a_{1}$ and $a_{2}$ are introduced:

$$
a_{1}=\frac{\left|\Delta M_{\mathrm{YSC}}\right|}{\Delta M_{\mathrm{YSC} \_0}}, \quad a_{2}=1-\frac{\mathrm{TTR}}{\mathrm{TTR}_{\mathrm{th}}},
$$

where $\Delta M_{\text {YSC_0 }}$ is the nominal value of additional yaw moment is $\Delta M_{\mathrm{YSC}}$ and $\mathrm{TTR}_{\mathrm{th}}$ is the nominal value of TTR. $\lambda_{1}$ and $\lambda_{2}$ can be calculated through (27) for coordination of the $\Delta M_{\mathrm{YSC}}$ and $\Delta M_{b_{-} \mathrm{RSC}}$ when YSC and RSC are 


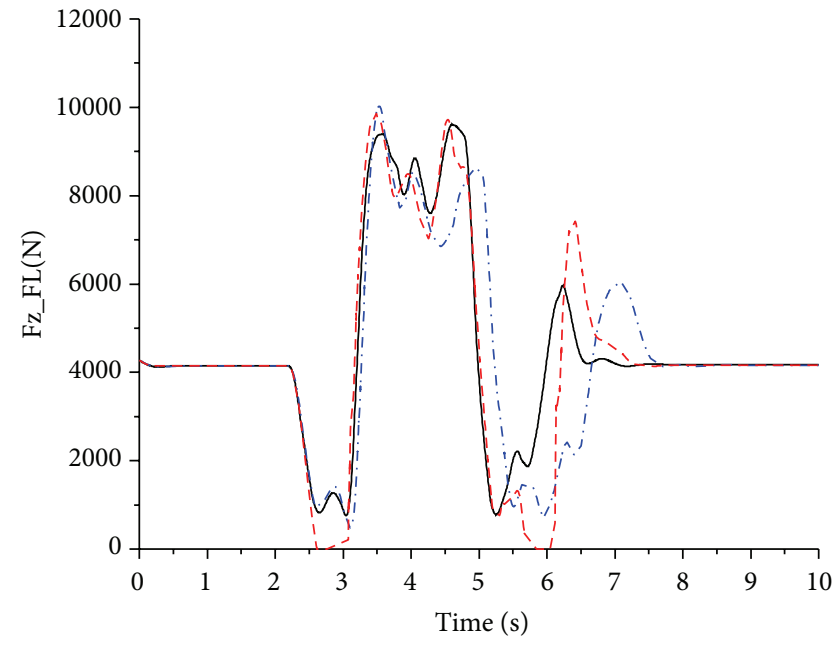

(a)

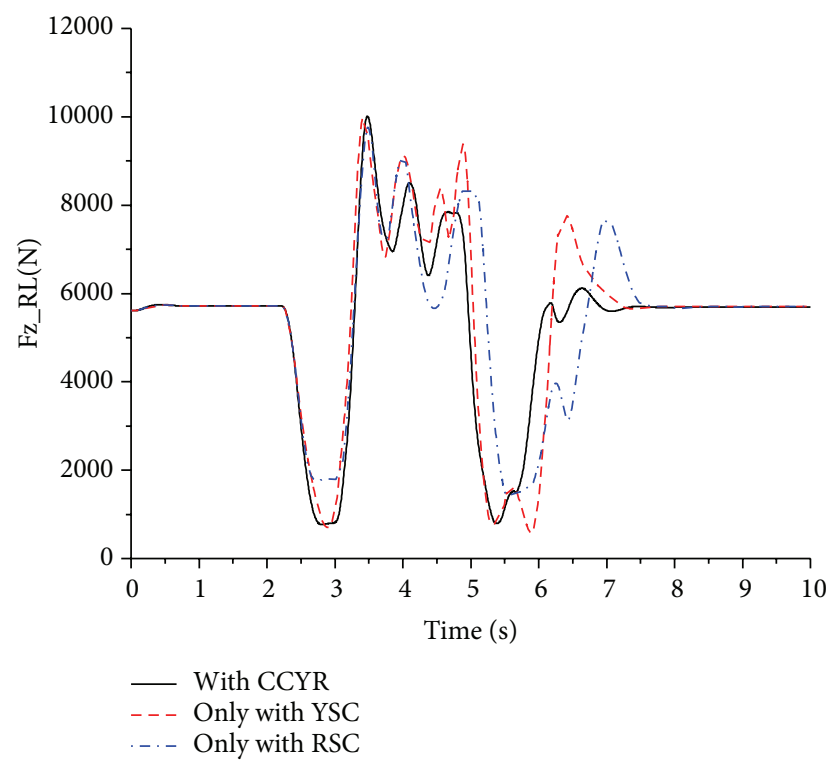

(c)

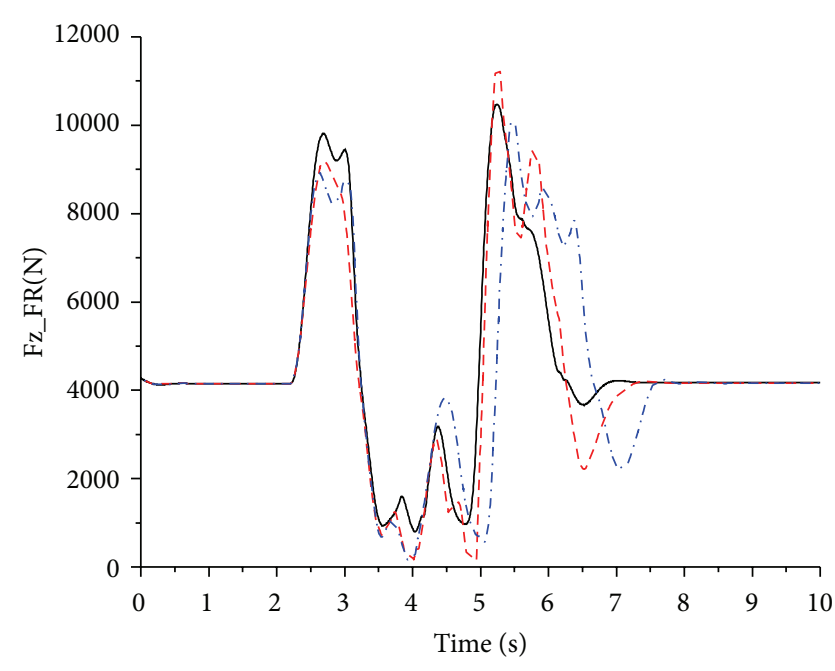

(b)

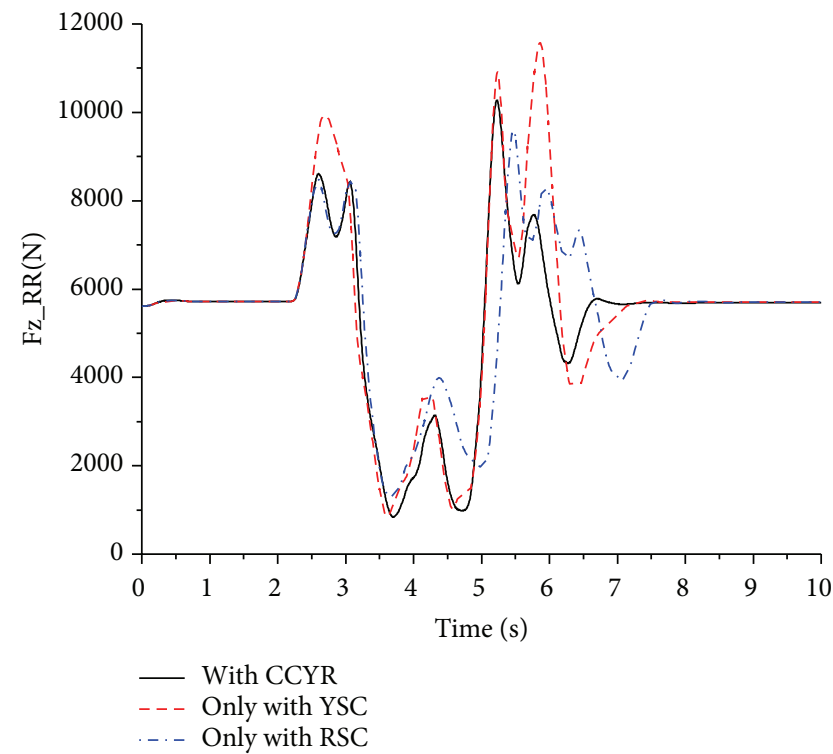

(d)

FIGURE 15: Wheel vertical force.

simultaneously triggered. $\lambda_{2}$ increases as the TTR decreases and $\lambda_{1}+\lambda_{2}=1$ :

$$
\begin{aligned}
& \lambda_{1}=\frac{a_{1}}{a_{1}+a_{2}}, \\
& \lambda_{2}=\frac{a_{2}}{a_{1}+a_{2}} .
\end{aligned}
$$

3.4. Design of ABS Controller. In order to prevent the wheel from being locked in braking and provide greater lateral force, ABS control is added to the coordinated control of yaw and roll stability. ABS control algorithm, mainly using the wheel acceleration and deceleration threshold method, is supplemented by reference slip rate threshold control. The comparisons between wheel acceleration and slip rate are carried out between vehicle data and corresponding threshold values. According to decision logic, the control command is sent to ABS hydraulic modulator to keep slip rate at the optimal value. As a result, the longitudinal or lateral force can obtain fully utilization, which will cause small braking distance and good yaw stability [25].

Figures 8 and 9 are the simulations of the ABS control algorithm. The simulation is straight line braking in uniform pavement (road surface with low adhesion and high adhesion) and the initial speed is $60 \mathrm{~km} / \mathrm{h}$. The adhesion coefficient of low adhesion surface is 0.2 , and the adhesion coefficient of high adhesion road is 0.8 .

The results show that the ABS control algorithm designed in this paper can realize good control effect in the general condition, and it is helpful for supplying a good foundation for the coordinated control of yaw and roll stability. 


\section{Simulation Results of Coordinated Control}

The proposed CCYR stability controller is implemented under the Simulink platform and simulated with the CarSim software package. To evaluate the control strategy, the algorithms of YSC and RSC are also established, respectively. And all the algorithms are evaluated through the vehicle simulation.

For each system, three simulations including slalom test under high adhesion, double-lane change test under high adhesion, and sine dwell test under high adhesion are conducted to test the rollover prevention capabilities. The same driver model is used for each rollover controller and each simulation. In these simulations, the antilock braking system (ABS) is used to prevent the lock of wheels.

4.1. Slalom Test under High Adhesion. The adhesion coefficient of slalom test is 1 , and the initial speed is $80 \mathrm{~km} / \mathrm{h}$.

As is shown in Figure 10, RSC vehicle has not completed the given trajectory, when the driver tries to operate the steering wheel. When RSC mainly controls front wheel braking, the lateral force of the outside front wheel reduces and saturates, so that the yaw moment reduces greatly, resulting in a greater dynamic vehicle understeer. In addition, the speed decreases greatly because the driving force reduces due to lateral force saturation. YSC vehicle follows the intent of the driver well and completes the given trajectory, and the speed changes a little. CCYR vehicle completes the given trajectory and the path is basically similar to that of YSC vehicle.

In Figures 11 and 12, the decrease of the sideslip angle and the roll angle is achieved by the RSC, which gives the smaller vehicle response than the RSC because of rapid tire load change. However, the erratic fluctuation of tire load under larger lateral acceleration increases the response time of controller. The delay of response time leads to instability of vehicle. The additional control moment is made because of the lager sideslip angle and the roll angle at the beginning of simulation test, which make the vehicle stabilize in the subsequent responds of vehicle. The CCYR stability controller combines the advantages of the YSC and RSC. Yaw rate, body roll angle, and sideslip angle of CCYR vehicle are relatively small, and consequently the vehicle has good yaw stability.

4.2. Double-Lane Change Test under High Adhesion. The adhesion coefficient of double-lane change test is 1 , and the initial speed is $130 \mathrm{~km} / \mathrm{h}$.

In Figure 13, RSC vehicle turns to understeer due to outside front wheel braking and has not completed the given trajectory, and the driver's steering wheel angle is greater. YSC vehicle follows the driver's intentions well and completed the given trajectory and has small changes in speed. CCYR vehicle completed the given trajectory and the path is basically similar to that of YSC vehicle.

In Figures 14 and 15, the changes of response signals including tire load, yaw rate, body roll angle and sideslip angle, are the same under larger lateral acceleration between the YSC and RSC, and the YSC or RSC is triggered separately

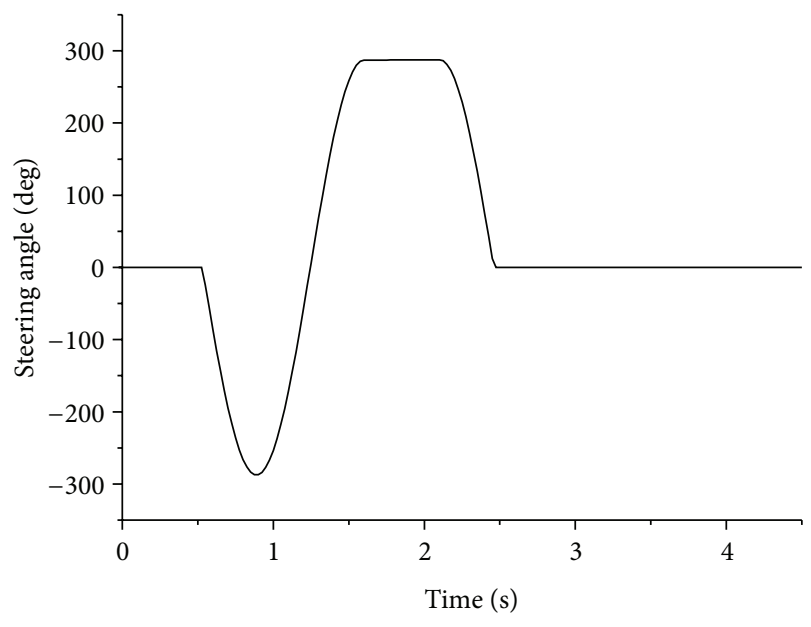

FIGURE 16: Steering angle.

and simultaneously to maximize achievement of the control target. The CCYR stability controller coordinates the YSC and RSC to control the system at the same time with coupling interaction. The results of simulations show that this control method has good control effectiveness.

4.3. Sine Dwell Test under High Adhesion. The adhesion coefficient of sine dwell test is 1 . The initial speed is $80 \mathrm{~km} / \mathrm{h}$. The input of steering wheel angle is a $0.7 \mathrm{~Hz}$ sine with a dwell maneuver. The maximum amplitude of steering wheel angle is 280 degrees, shown in Figure 16. The tests were carried out in CarSim.

In Figure 17, the YSC and the RSC demonstrate their effectiveness in achieving enhanced vehicle stability by their performance in the NHTSA sine-with-dwell tests. Compared to the RSC, the values of response signals including yaw rate, body roll angle, and sideslip angle are larger for the YSC. The small fluctuations of response signals make the stable time of vehicle longer with the RSC. Figure 17 shows that the maximum values of yaw rate and sideslip angle of the proposed CCRY are always smaller than those of the uncoordinated system, which demonstrate that the new control algorithm has certain enhancement in the comfortable and stability of vehicle.

\section{Conclusion}

In this paper the coordinated control strategy of yaw and rollover stability is developed. A nonlinear 3-DoF vehicle prediction model is built and tested. The YSC traces the yaw motion and the sideslip error with a 3-DoF vehicle model via differential braking. The RSC applies a braking force according to the TTR threshold and TTR estimation with a 3-DoF nonlinear prediction vehicle model of the vehicle. Simulation is implemented on CarSim electronic stability control platform by the comparison among CCYR, YSC, and RSC. The results can be summarized as follows. 


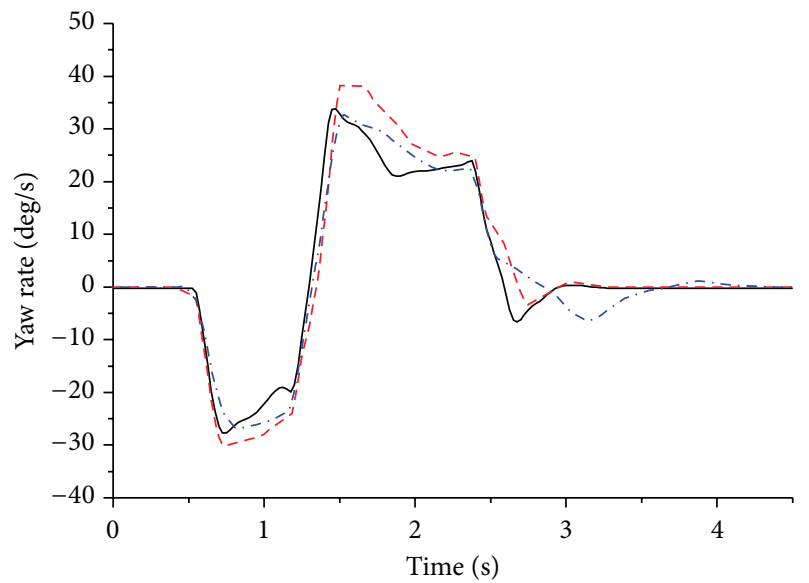

(a)

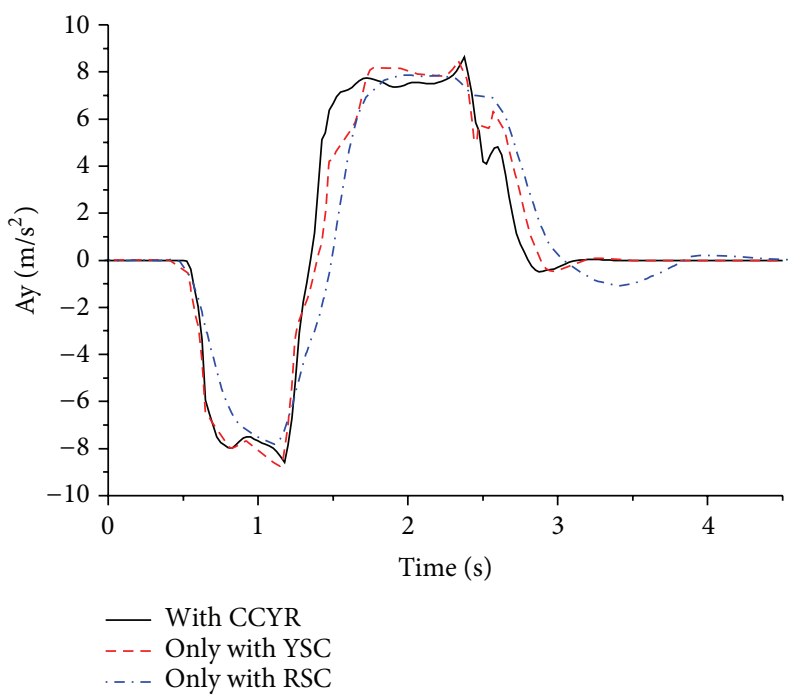

(c)

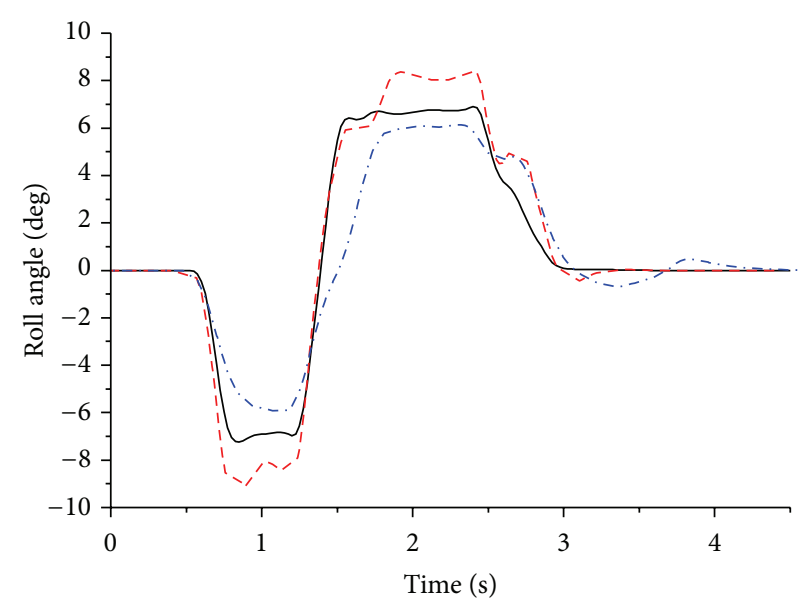

(b)

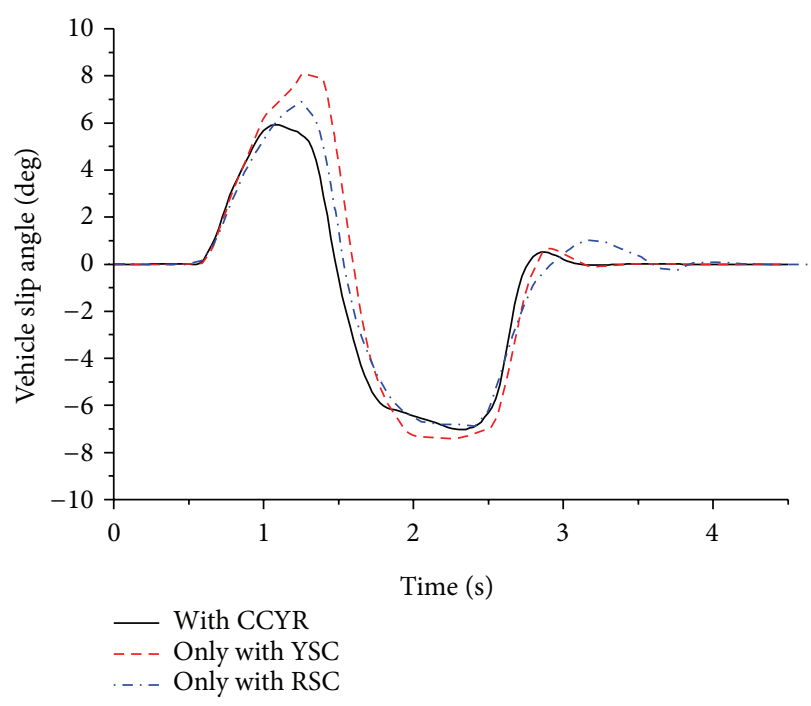

(d)

FIGURE 17: Yaw rate, roll angle, lateral acceleration and sideslip angle.

(1) The nonlinear 3-DoF vehicle model is built up and tested, and the results show that the model has very high simulation accuracy.

(2) The coordinated control algorithm has better stability of yaw and roll than YSC and RSC.

(3) As the rollover predictive model, the proposed nonlinear 3-DoF vehicle model is effective for the coordinated control algorithm.

\section{Nomenclature}

a: Distance from center of gravity (CG) to front axle

$b$ : Distance from CG to rear axle

$t$ : Track width

$k_{f}$ : Front tire cornering stiffness

$k_{r}$ : Rear tire cornering stiffness

$m$ : Total mass of vehicle

$m_{s}$ : Sprung mass of vehicle
$I_{z}: \quad$ Inertia around the $z$-axis

$I_{x z}$ : Inertia around the $z$-axis and $x$-axis

$I_{z s}$ : Inertia around the $z$-axis of sprung mass

$I_{x z s}:$ Inertia around the $z$-axis and $x$-axis of sprung mass

g: Gravity acceleration

$e$ : Distance between the center of sprung mass and the vehicle roll axis

$C_{\varphi}$ : Roll damping

$F_{y f}$ : Front tire lateral force

$F_{y r}$ : Rear tire lateral force

FL: Left side tire vertical force

FR: Right side tire vertical force

$K_{\varphi}:$ Roll stiffness

$M_{x}$ : Roll moment

$M_{z}$ : Yaw moment

$V_{x}:$ Longitudinal vehicle speed

$V_{y}$ : Lateral vehicle speed 
$\dot{V}_{y}:$ Lateral vehicle acceleration

$\delta_{f}$ : Front tire steer angle

$\alpha_{f}$ : Front tire slip angle

$\alpha_{r}$ : Rear tire slip angle

$\beta$ : Vehicle sideslip angle

$\gamma$ : Yaw angle

$r$ : Yaw rate

$\dot{r}$ : Yaw angular acceleration

$\varphi$ : Roll angle of vehicle body

$\ddot{\varphi}$ : Roll angular acceleration of vehicle body

$\mu$ : Tire-road friction coefficient.

\section{Acknowledgments}

The authors thank the "research team of test technology on the active safety of automobile." The work is sponsored by Shanghai Automobile Incorporation Company Industrial Technology Development Fund (SAIC Grant 1007).

\section{References}

[1] P. L. Boyd, "NHTSA's NCAP rollover resistance rating system," in Proceedings of the 19th International Technical Conference on the Enhanced Safety of Vehicles, 2005.

[2] Motor vehicle traffic crash injury and fatality estimates. National Highway Traffic Safety Administration, 2003.

[3] V. Cherian, R. Shenoy, A. Stothert, J. Shriver, J. Ghidella, and T. D. Gillespie, "Model-Based Design of a SUV anti-rollover control system," SAE paper 2008-01, 2008.

[4] J. S. Tang, "Active roll and stability control," SAE International Journal of Passenger Cars, vol. 1, no. 1, pp. 1060-1070, 2009.

[5] D. Hyun, "Predictive modeling and active control of rollover in heavy vehicles," Texas A\&M University, 2001.

[6] J. Preston-Thomas and J. Woodrooffe, "A feasibility study of a rollover warning device for heavy trucks," Transport Canada Publication TP 10610E, 1990.

[7] R. D. Ervin, C. B. Winkler, P. S. Fancher et al., "Cooperative agreement to foster the deployment of a heavy vehicle intelligent dynamic stability enhancement system," Interim Report NHTSA-U.S. DOT Contract DTNH22-95-H-07002, 1998.

[8] B.-C. Chen, Warning and control for vehicle rollover prevention [Ph.D. thesis], Department of Mechanical Engineering and Applied Mechanics, University of Michigan, 2001.

[9] A. Y. Lee, "Coordinated control of steering and anti-roll bars to alter vehicle rollover tendencies," Journal of Dynamic Systems, Measurement and Control, Transactions of the ASME, vol. 124, no. 1, pp. 127-132, 2002.

[10] S. Yoon, J. Jung, and B. Koo, "Development of rollover prevention system using unified chassis control of ESP and CDC systems," SAE 2006-01-1276, 2006.

[11] M. Kamal, "Development of Active Suspension Control for Combined Handling and Rollover Propensity Enhancement," SAE SP 2007-01-0826, 2007.

[12] J. Yoon, D. Kim, and K. Yi, "Design of a rollover index-based vehicle stability control scheme," Vehicle System Dynamics, vol. 45, no. 5, pp. 459-475, 2007.

[13] J. Yoon, W. Cho, B. Koo, and K. Yi, "Unified chassis control for rollover prevention and lateral stability," IEEE Transactions on Vehicular Technology, vol. 58, no. 2, pp. 596-609, 2009.
[14] B. Guvenc, T. Acarman, and L. Guvenc, "Coordination of steering and individual wheel braking actuated vehicle yaw stability control," in Proceedings of the IEEE Intelligent Vehicles Symposium, pp. 288-293, IEEE, 2003.

[15] M. A. Selby, Intelligent vehicle motion control [Ph.D. dissertation], University of Leeds, 2003.

[16] Y. Kou, H. Peng, and D. Jung, "Development of an integrated chassis control system for worst-case studies," in Proceedings of AVEC, pp. 47-52, 2006.

[17] H. Chou and B. D’Andréa-Novel, "Global vehicle control using differential braking torques and active suspension forces," Vehicle System Dynamics, vol. 43, no. 4, pp. 261-284, 2005.

[18] D. Li, S. Du, and F. Yu, "Integrated vehicle chassis control based on direct yaw moment, active steering and active stabiliser," Vehicle System Dynamics, vol. 46, no. 1, pp. 341-351, 2008.

[19] J. Yoon, S. Yim, W. Cho, B. Koo, and K. Yi, "Design of an unified chassis controller for rollover prevention, manoeuvrability and lateral stability," Vehicle System Dynamics, vol. 48, no. 11, pp. 1247-1268, 2010.

[20] B.-C. Chen, C.-C. Yu, W.-F. Hsu, and M.-F. Lo, "Design of electronic stability control for rollover prevention using sliding mode control," International Journal of Vehicle Design, vol. 56, no. 1-4, pp. 224-245, 2011.

[21] D. Odenthal, T. Bunte, and J. Ackermann, "Nonlinear steering and braking control for vehicle rollover avoidance," in Proceedings of the European Control Conference, Karlsruhe, Germany, 1999.

[22] B.-C. Chen and H. Peng, "Differential-braking-based rollover prevention for sport utility vehicles with human-in-the-loop evaluations," Vehicle System Dynamics, vol. 36, no. 4-5, pp. 359389, 2001.

[23] A. Sorniotti and N. D'Alfio, "Vehicle dynamics simulation to develop an active roll control system," SAE Papers 01-0828, 2007.

[24] Q. Z. Yan, J. M. Williams, J. Li, Q. Z. Yan-Daimler Chrysler, J. M. Williams-Daimler Chrysler, and J. Li-Daimler Chrysler, "Chassis control system development using simulation: software in the loop, rapid prototyping, and hardware in the loop," in Proceedings of the SAE Conference, pp. 1-12, 2002.

[25] H. Ding, K. Guo, J. Zhang, H. Fu, and J. Lv, "Development and application of the hardware and driver-in-the-loop test rig for automotive electronic stability programs automotive engineering," 2006-04, 2006. 


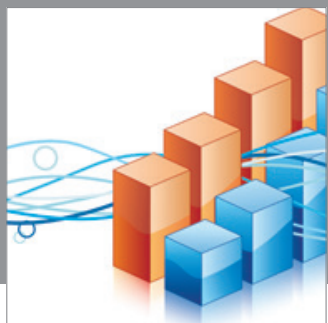

Advances in

Operations Research

mansans

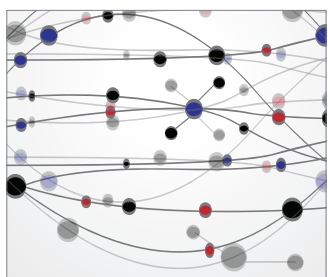

The Scientific World Journal
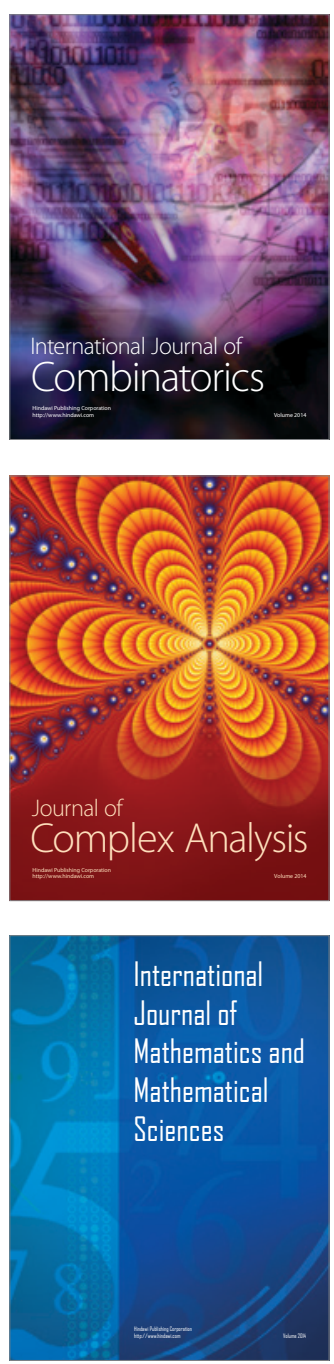
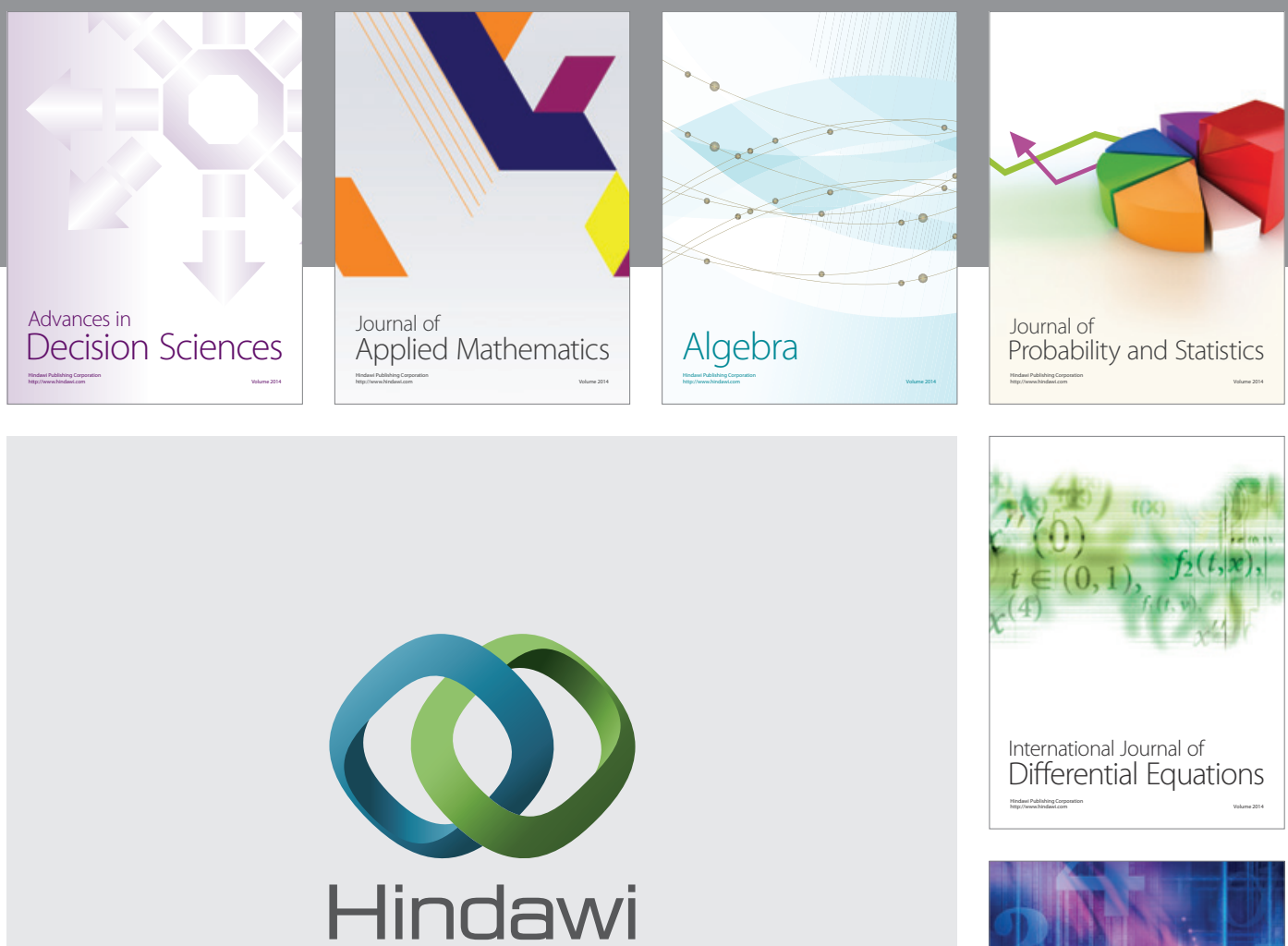

Submit your manuscripts at http://www.hindawi.com
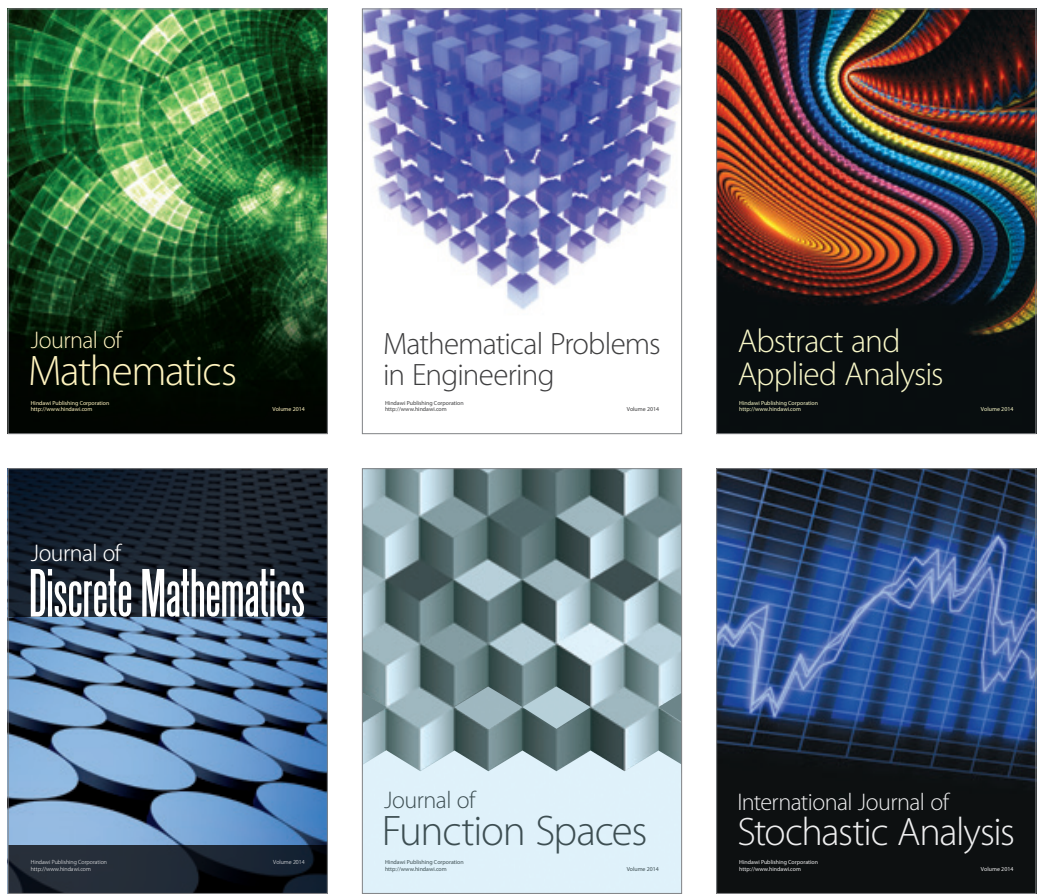

Journal of

Function Spaces

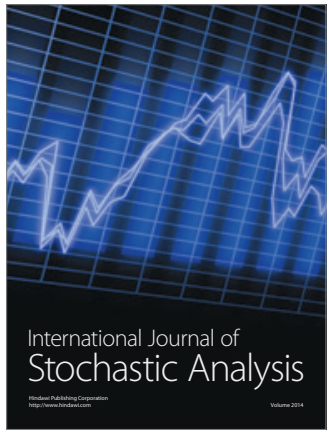

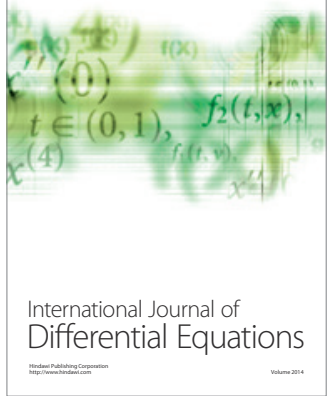
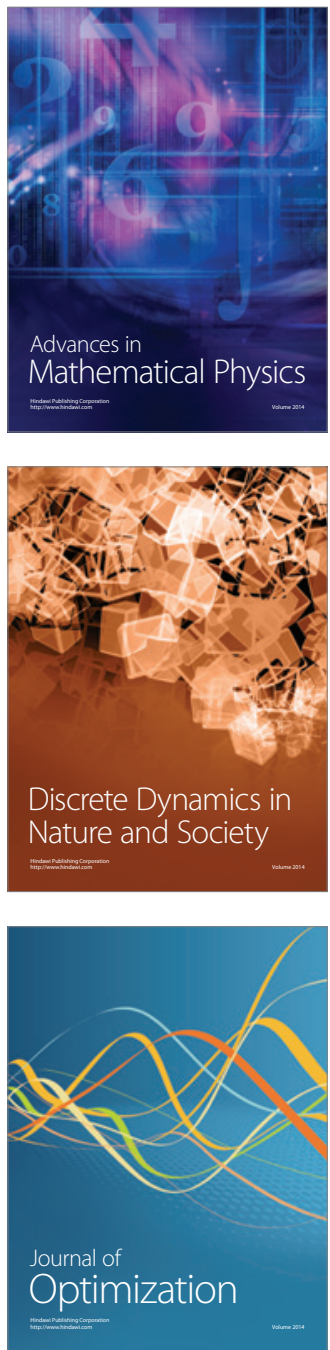